\title{
A first-principles study of carbon-related energy levels in GaN: Part II - Complexes formed by carbon and hydrogen, silicon or oxygen
}

\author{
Masahiko Matsubara and Enrico Bellotti \\ Department of Electrical and Computer Engineering, \\ Boston University, 8 St. Mary's Street, Boston, MA 02215, USA
}

(Dated: September 24, 2018)

\begin{abstract}
This work presents an in-depth investigation of the properties of complexes composed of hydrogen, silicon or oxygen with carbon, which are major unintentional impurities in undoped GaN. This manuscript is a complement to our previous work on carbon-carbon and carbon-vacancy complexes. We have employed a first-principles method using Heyd-Scuseria-Ernzerhof hybrid functionals within the framework of generalized Kohn-Sham density functional theory. Two H-C, four Si-C and five $\mathrm{O}-\mathrm{C}$ complexes in different charge states have been considered. After full geometry relaxations, formation energies, binding energies and both thermal and optical transition levels were obtained. The calculated energy levels have been systematically compared with the experimentally observed carbon related trap levels. Furthermore, we computed vibrational frequencies for selected defect complexes and defect concentrations were estimated in the low, mid and high carbon doping scenarios considering two different cases where electrically active defects: (a) only carbon and vacancies and (b) not only carbon and vacancies but also hydrogen, silicon and oxygen. We confirmed that $\mathrm{C}_{\mathrm{N}}$ is a dominant acceptor in GaN. In addition to it, substantial amount of $\mathrm{Si}_{\mathrm{Ga}}-\mathrm{C}_{\mathrm{N}}$ complex exists in a neutral form. This complex is a likely candidate for unknown form of carbon observed in undoped $n$-type GaN.

PACS numbers: 61.72.J-, 61.72.uj, 71.15.Mb, 71.55.Eq
\end{abstract}

\section{INTRODUCTION}

Carbon is ubiquitous in GaN regardless of intentional doping or growth techniques. The incorporated carbon introduce trap levels within the band gap, which cause undesirable effect on the performance of GaN-based optoor power-electronics devices. Therefore, it is important to identify the physical form of carbon, which causes the trap levels, in order to control its impact of device operation. Experimental methods such as deep level transient spectroscopy (DLTS), deep level optical spectroscopy (DLOS) and related techniques have been used for GaN samples with different carbon concentration and multiple trap levels have been observed to be function of the carbon presence ${ }^{1-4}$. Unfortunately, these techniques are not capable of identifying the original forms of the trap levels directly. In this regard computational approach is of great help to interpret the experimental results.

In a companion paper to this manuscript ${ }^{5}$ we have focused on the complexes formed by pairs of two carbons $\left(\mathrm{C}_{\mathrm{N}}-\mathrm{C}_{\mathrm{Ga}}, \mathrm{C}_{\mathrm{I}}-\mathrm{C}_{\mathrm{N}}\right.$ and $\mathrm{C}_{\mathrm{I}}-\mathrm{C}_{\mathrm{Ga}}$, where $\mathrm{C}_{\mathrm{N}}$ is a $\mathrm{C}$ at $\mathrm{N}$ site, $\mathrm{C}_{\mathrm{Ga}}$ is a $\mathrm{C}$ at $\mathrm{Ga}$ site and $\mathrm{C}_{\mathrm{I}}$ is an interstitial $\mathrm{C}$ ) and pairs of carbon and nearest neighbor vacancy $\left(\mathrm{C}_{\mathrm{N}}-\mathrm{V}_{\mathrm{Ga}}\right.$ and $\mathrm{C}_{\mathrm{Ga}}-\mathrm{V}_{\mathrm{N}}$, where $\mathrm{V}_{\mathrm{Ga}}$ is a Ga vacancy and $\mathrm{V}_{\mathrm{N}}$ is a $\mathrm{N}$ vacancy), for which our knowledge is still limited, as candidates for the origins of carbon related deep level traps observed in experiments and tried to identify them by comparing our calculated results with experimental data. As a result, we successfully assigned carbon-related energies reported by different experimental groups to our theoretically determined trap levels with specific forms of $\mathrm{C}$. However, the formation energies of some of these complexes are substantial (e.g. the formation energy of the neutral charge state of $\mathrm{C}_{\mathrm{N}}-\mathrm{V}_{\mathrm{Ga}}$ complex is almost $10 \mathrm{eV})$, resulting in very low concentrations, much below the experimental detection limit. In the present article we extend our search of C-related complexes to the ones formed by hydrogen, silicon or oxygen in order to complement the results with the ones in our previous work ${ }^{5}$. These three elements are also well-known as common unintentional impurities in GaN, alongside with carbon.

Silicon is used to obtain controlled $n$-type conductivity in $\mathrm{GaN}^{6-9}$. Oxygen was experimentally identified as donor due to unintentional doping, which leads to a very high $n$-type conductivity ${ }^{10}$. Theoretical calculations have shown that the Si substituting $\mathrm{Ga}$ atom $\left(\mathrm{Si}_{\mathrm{Ga}}\right)$ and the $\mathrm{O}$ substituting nitrogen atom $\left(\mathrm{O}_{\mathrm{N}}\right)$ act as shallow donors with low formation energies ${ }^{11,12}$. Complexes based on $\mathrm{Si}_{\mathrm{Ga}}$ and $\mathrm{O}_{\mathrm{N}}$ have also been studied. $\mathrm{O}_{\mathrm{N}}-\mathrm{C}_{\mathrm{N}}$ has been indicated as a possible culprit for the origins of yellow luminescence ${ }^{13}$. On the other hand, a recent study concluded that neither $\mathrm{O}_{\mathrm{N}}-\mathrm{C}_{\mathrm{N}}$ nor $\mathrm{Si}_{\mathrm{Ga}}-\mathrm{C}_{\mathrm{N}}$ can be the origins of the yellow luminescence in $\mathrm{GaN}^{14}$. It has also been speculated that hydrogen forms complexes with impurities in GaN and could modify its electronic behavior. Hydrogen atoms neutralize $\mathrm{Mg}$ acceptors in $\mathrm{GaN}^{15-17}$ and complexes of multiple hydrogens with native defects, in particular vacancies, have also been investigated $^{18,19}$. Furthermore, complexes of hydrogen with carbon, have also been also studied in relation to the blue luminescence ${ }^{20}$. As a result, it is possible that complexes formed by these elements ( $\mathrm{Si}, \mathrm{O}$ and $\mathrm{H}$ ) with carbon lead to trap levels within the band gap, which are experimentally detected as carbon related energy levels.

In this manuscript we provide a comprehensive study 
of C-based complexes with other unintentional dopants ( $\mathrm{H}, \mathrm{Si}$ and $\mathrm{O}$ ) within the framework of generalized KohnSham density functional theory using Heyd-ScuseriaErnzerhof hybrid density functionals. Formation energies, binding energies and both thermal and optical activation energies are obtained from the total energies of fully optimized complex structures in the different charge states. By assigning our calculated energy levels to the experimentally measured ones we try to identify the origins of C-related trap levels, especially for those whose exact physical forms are not known yet. In addition, concentrations of $\mathrm{C}$ impurities/complexes are estimated for each form of $\mathrm{C}$ impurities. Acceptor form of $\mathrm{C}\left(\mathrm{C}_{\mathrm{N}}^{1-}\right)$ is known to be dominant in $\mathrm{GaN}^{21-24}$. However, secondary ion mass spectroscopy (SIMS) experiment reported in Ref. 25 for $n$-type GaN indicated that carbon concentration is always higher than the carrier concentration. This result implies that not all of the carbon takes the form of $\mathrm{C}_{\mathrm{N}}^{1-}$ and that substantial amount of other forms of carbon would exist in $n$-type GaN. Our concentration analysis provides an potential candidate for this unknown form of carbon.

This manuscripts is organized as follows: in Section II, the computational methods are briefly outlined as the detail are similar to the ones presented in our companion work ${ }^{5}$. In Section III, we will present our calculated results for $\mathrm{H}, \mathrm{Si}$ and $\mathrm{O}$ impurities and complexes with $\mathrm{C}$. Our theoretical trap levels are assigned to experimentally observed ones and concentration analysis is performed in Section IV. Section V concludes this paper.

\section{METHODS}

Details of the computational methods were already given in the first part of this work ${ }^{5}$, and they are only briefly outlined here. Our calculations were performed using Heyd-Scuseria-Ernzerhof (HSE) hybrid density functional $^{26,27}$ implemented in the VASP code ${ }^{28,29}$. The mixing amount of exact exchange was taken to be $28 \%$, which gives $3.45 \mathrm{eV}$ band gap value for bulk GaN.

The formation energies of a defect $(D)$ with a charge state $q, E_{f}^{q}\left(D, E_{F}\right)$, are calculated from the total energy of the system, $E_{\text {tot }}^{q}(D)$, and its bulk counterpart, $E_{\mathrm{bulk}}$, as well as chemical potentials for the defect type $\mathrm{X}, \mu_{\mathrm{X}}$, as a function of Fermi energy $\left(E_{F}\right)$, which is set to zero at the valence band maximum $\left(E_{v}\right)$, i.e.

$$
\begin{aligned}
E_{f}^{q}\left(D, E_{F}\right) & =E_{\mathrm{tot}}^{q}(D)-E_{\mathrm{bulk}}-\sum_{\mathrm{X}} n_{\mathrm{X}} \mu_{\mathrm{X}} \\
& +q\left(E_{F}+E_{v}\right)+\Delta E_{\mathrm{corr}}^{q} .
\end{aligned}
$$

Here $n_{\mathrm{X}}$ is the number of defect type $\mathrm{X}$, which are added to or removed from the system, and the last term corresponds to the correction for the charged defects in the finite supercell ${ }^{30-32}$. The chemical potentials for $\mathrm{Ga}, \mathrm{N}$ and $\mathrm{C}$ are obtained from bulk $\alpha$-Ga, nitrogen molecule and diamond, respectively, whereas those for $\mathrm{H}, \mathrm{O}$ and
Si are obtained as follows. The chemical potential for $\mathrm{H}$ $\left(\mu_{\mathrm{H}}\right)$ is determined using an isolated $\mathrm{H}_{2}$ molecule as a reference. The chemical potentials for oxygen $\left(\mu_{\mathrm{O}}\right)$ and silicon $\left(\mu_{\mathrm{Si}}\right)$ depend on the growth conditions due to the possible formations of $\mathrm{Ga}_{2} \mathrm{O}_{3}$ and $\mathrm{Si}_{3} \mathrm{~N}_{4}$, respectively. As a result, they must satisfy specific conditions shown below. For $\mathrm{Si}_{3} \mathrm{~N}_{4}$, the condition is written as

$$
3 \mu_{\mathrm{Si}}+4 \mu_{\mathrm{N}}=3 E(\mathrm{Si})+2 E\left(\mathrm{~N}_{2}\right)+\Delta H_{f}\left(\mathrm{Si}_{3} \mathrm{~N}_{4}\right),
$$

where $E(\mathrm{Si}), E\left(\mathrm{~N}_{2}\right)$ and $\Delta H_{f}\left(\mathrm{Si}_{3} \mathrm{~N}_{4}\right)$ are the energies of bulk silicon and nitrogen molecule and the formation enthalpy of the $\beta-\mathrm{Si}_{3} \mathrm{~N}_{4}$, respectively. Our calculated value for $\Delta H_{f}\left(\mathrm{Si}_{3} \mathrm{~N}_{4}\right)$ is $-8.52 \mathrm{eV}$, which is in good agreement with the experimental value $(-8.58 \mathrm{eV})^{33}$. With the Eq. (2) and the condition for GaN

$$
\mu_{\mathrm{Ga}}+\mu_{\mathrm{N}}=E(\mathrm{Ga})+\frac{1}{2} E\left(\mathrm{~N}_{2}\right)+\Delta H_{f}(\mathrm{GaN}),
$$

in Ga-rich limit $\mu_{\mathrm{Si}}$ is computed as

$\mu_{\mathrm{Si}}(\mathrm{Ga}-\operatorname{rich})=E(\mathrm{Si})+\frac{1}{3} \Delta H_{f}\left(\mathrm{Si}_{3} \mathrm{~N}_{4}\right)-\frac{4}{3} \Delta H_{f}(\mathrm{GaN})$,

whereas in N-rich limit it is computed as

$$
\mu_{\mathrm{Si}}(\mathrm{N}-\text { rich })=E(\mathrm{Si})+\frac{1}{3} \Delta H_{f}\left(\mathrm{Si}_{3} \mathrm{~N}_{4}\right) .
$$

For $\mathrm{Ga}_{2} \mathrm{O}_{3}$, it is also written as

$$
2 \mu_{\mathrm{Ga}}+3 \mu_{\mathrm{O}}=2 E(\mathrm{Ga})+\frac{3}{2} E\left(\mathrm{O}_{2}\right)+\Delta H_{f}\left(\mathrm{Ga}_{2} \mathrm{O}_{3}\right),(6)
$$

where $E(\mathrm{Ga}), E\left(\mathrm{O}_{2}\right)$ and $\Delta H_{f}\left(\mathrm{Ga}_{2} \mathrm{O}_{3}\right)$ are the energies of bulk $\alpha$-Ga and oxygen molecule and the formation enthalpy of the $\beta-\mathrm{Ga}_{2} \mathrm{O}_{3}$, respectively. Our calculated value for $\Delta H_{f}\left(\mathrm{Ga}_{2} \mathrm{O}_{3}\right)$ is $-10.00 \mathrm{eV}$, which is close to the experimental value $(-11.29 \mathrm{eV})^{34}$. With the Eqs. (3) and (6), $\mu_{\mathrm{O}}$ in Ga-rich limit becomes

$$
\mu_{\mathrm{O}}(\mathrm{Ga}-\text { rich })=\frac{1}{2} E\left(\mathrm{O}_{2}\right)+\frac{1}{3} H_{f}\left(\mathrm{Ga}_{2} \mathrm{O}_{3}\right),
$$

whereas in N-rich it becomes

$$
\mu_{\mathrm{O}}(\mathrm{N}-\operatorname{rich})=\frac{1}{2} E\left(\mathrm{O}_{2}\right)+\frac{1}{3} H_{f}\left(\mathrm{Ga}_{2} \mathrm{O}_{3}\right)-\frac{2}{3} H_{f}(\mathrm{GaN}) .
$$

Using the computed formation energies, the thermodynamic transition level between charge states $q$ and $q^{\prime}$ is obtained with

$$
\epsilon\left(q / q^{\prime}\right)=\frac{E_{f}^{q}\left(D, E_{F}=0\right)-E_{f}^{q^{\prime}}\left(D, E_{F}=0\right)}{q^{\prime}-q},
$$

which corresponds to the experimentally observed trap levels by thermal techniques such as DLTS. By adding Franck-Condon shift, optical levels can be also obtained from eq. (9), which corresponds to the experimentally observed trap levels by optical techniques such as DLOS. 
The concentration, $[\mathrm{C}]$, of an impurity with the formation energy $E_{f}$ is obtained with

$$
[\mathrm{C}]=N_{\text {site }} N_{\text {config }} \exp \left(\frac{-E_{f}}{k_{\mathrm{B}} T}\right),
$$

where $N_{\text {site }}$ is the number of sites per unit volume and $N_{\text {config }}$ is the number of equivalent configurations the defect can take. For example, in the case of substitutional impurity such as $\mathrm{C}_{\mathrm{N}}, N_{\text {config }}=1$ and in the case of $\mathrm{Si}_{\mathrm{Ga}}-\mathrm{C}_{\mathrm{N}}$ complex, $N_{\text {config }}=4$.

\section{RESULTS}

\section{A. Hydrogen Impurities}

In this section we discuss interstitial $\mathrm{H}$ and its complex with two substitutional impurity of carbon, i.e. $\mathrm{C}_{\mathrm{N}}$ and $\mathrm{C}_{\mathrm{Ga}}$. First we determine the most favorable configurations of $\mathrm{H}_{\mathrm{I}}$ in various charge states. Then we consider their complexes with $\mathrm{C}_{\mathrm{N}} / \mathrm{C}_{\mathrm{Ga}}$ and obtain the lowest energy states.

\section{Interstitial Hydrogen}

As initial configurations for $\mathrm{H}_{\mathrm{I}}$, we considered following six different sites, i.e. $\mathrm{BC}_{\|}, \mathrm{BC}_{\perp}, \mathrm{AB}_{\|}, \mathrm{AB}_{\perp}$, octahedral and tetrahedral interstitial positions. $\mathrm{BC}$ represents the bond-centered sites and $\mathrm{AB}$ represents the anti-bonding sites. Both $\mathrm{BC}$ and $\mathrm{AB}$ sites have two different variations. For example, in the case of the $\mathrm{BC}$ position, when $\mathrm{H}$ is located between $\mathrm{Ga}-\mathrm{N}$ bonds parallel to $c$-axis, it is denoted as $\mathrm{BC}_{\|}$, whereas when $\mathrm{H}$ is located between $\mathrm{Ga}-$ $\mathrm{N}$ bonds (virtually) perpendicular to $c$-axis, it is denoted as $\mathrm{BC}_{\perp}$. Then all the configurations were fully relaxed within HSE.

For the $1+$ charge state, $\mathrm{BC}_{\|}$position is the most stable. This structure is given in FIG. 1 (a). The distance between $\mathrm{H}$ and $\mathrm{N}\left(d_{\mathrm{H}-\mathrm{N}}\right)$ is $1.01 \AA$, whereas the distance between $\mathrm{H}$ and $\mathrm{Ga}\left(d_{\mathrm{H}-\mathrm{Ga}}\right)$ is $1.93 \AA$. The $\mathrm{Ga}$ atom is pushed down by the $\mathrm{H}$ atom and is located in the Natom plane.

For the 0 (neutral) and 1 - charge states, $\mathrm{H}$ takes the octahedral interstitial position. The structures are shown in FIGs. 1 (b) and (c) for the 0 and 1 - charge states, respectively. For the 0 charge state, average $d_{\mathrm{H}-\mathrm{N}}$ is $2.28 \AA$, while for the $1-$ charge state, average $d_{\mathrm{H}-\mathrm{N}}$ is $2.33 \AA$. These structural properties are very similar to those obtained in previous LDA/GGA based calculations ${ }^{35,36}$.

The calculated formation energies for $\mathrm{H}_{\mathrm{I}}$ in different charge states are shown in FIG. 2. The formation energies for $\mathrm{C}_{\mathrm{N}}$ both in Ga-rich and $\mathrm{N}$-rich conditions are also given as references with dotted lines in the figure. $\mathrm{H}_{\mathrm{I}}^{+}$is the most stable state up to $2.99 \mathrm{eV}$ above the VBM and $\mathrm{H}_{\mathrm{I}}{ }^{-}$becomes the most stable when the Fermi energy is higher than $2.99 \mathrm{eV}$. The neutral $\mathrm{H}_{\mathrm{I}}^{0}$ never becomes a stable charge state at all Fermi levels within the band gap.
The $(+/-)$ transition level of $2.99 \mathrm{eV}$ in our HSE result is in good agreement with previously obtained HSE results $^{20,37}$, although it is in contrast to the values obtained in previous $\mathrm{LDA}^{35}$ and $\mathrm{GGA}^{36}$ calculations, which were $2.10 \mathrm{eV}$ and $1.98 \mathrm{eV}$, respectively.

We also considered a $\mathrm{H}_{2}$ molecule as a possible form of the interstitial hydrogen in GaN. The octahedral and tetrahedral positions were selected as initial positions of the $\mathrm{H}_{2}$ molecule and they were fully relaxed within HSE. We found that only the 0 charge state is the most stable at all the Fermi energy as shown in blue dashed line in FIG. 2. The structure is shown in FIG. 1 (d). The direction of the $\mathrm{H}-\mathrm{H}$ bond of $\mathrm{H}_{2}$ molecule is parallel to the $c$-axis and the bond length is $0.73 \AA$. $\mathrm{H}_{2}^{0}$ has lower formation energy than $\mathrm{H}_{\mathrm{I}}^{0}$, but never becomes stable because its formation energy is always higher than those of $\mathrm{H}_{\mathrm{I}}^{+}$or $\mathrm{H}_{\mathrm{I}}^{-}$. This result is in contrast to the previous LDA/GGA based calculations, where $\mathrm{H}_{2}^{0}$ was expected to be the most stable state around the middle of the band gap $^{35,36}$. The difference between the previous results and our HSE result stem from the difference of the reference energy for $\mathrm{H}$ atom rather than the difference introduced by the functionals that were employed. In Refs. 35 and $36, \mu_{\mathrm{H}}$ is obtained from the energy of a $\mathrm{H}$ atom, whereas we obtain it from the half of the energy of a $\mathrm{H}_{2}$ molecule. Indeed, we found that if we use the $\mu_{\mathrm{H}}$ taken from a $\mathrm{H}$ atom in our HSE calculations, the formation energy of $\mathrm{H}_{2}^{0}$ is lowered and becomes stable around the middle of the band gap as in the cases of LDA/GGA.

\section{Complexes of Hydrogen with Carbon}

We turn our attention to the complex made of $\mathrm{C}$ and $\mathrm{H}$. Both $\mathrm{C}_{\mathrm{N}}$ and $\mathrm{C}_{\mathrm{Ga}}$ were considered as a constituent of the complex. One of the $\mathrm{N}(\mathrm{Ga})$ atoms is replaced by $\mathrm{C}$ to make a $\mathrm{C}_{\mathrm{N}}\left(\mathrm{C}_{\mathrm{Ga}}\right)$ and a $\mathrm{H}$ atom is placed interstitial positions around the $\mathrm{C}_{\mathrm{N}}\left(\mathrm{C}_{\mathrm{Ga}}\right)$ like in the case of $\mathrm{H}_{\mathrm{I}}$ and the structures are fully relaxed within HSE.

Formation energies of $\mathrm{C}_{\mathrm{N}}-\mathrm{H}_{\mathrm{I}}$ and $\mathrm{C}_{\mathrm{Ga}}-\mathrm{H}_{\mathrm{I}}$ complex are reported with a green and red solid lines, respectively, in FIG. 3, with those of the $\mathrm{C}_{\mathrm{N}}$ with a blue dashed line, $\mathrm{C}_{\mathrm{Ga}}$ with a cyan dashed line, $\mathrm{C}_{\mathrm{N}}-\mathrm{C}_{\mathrm{Ga}}$ with a magenta dashed line, and $\mathrm{H}_{\mathrm{I}}$ with a black solid line as references. Both complexes have only two charge states with energies within the band gap. For the $\mathrm{C}_{\mathrm{N}}-\mathrm{H}_{\mathrm{I}}$ complex, in the very narrow region up to $0.09 \mathrm{eV}$ above the VBM, the $1+$ charge state is the most stable. Above $0.09 \mathrm{eV}$, the 0 (neutral) charge state is the most stable up to the CBM. This clearly suggests that the $\mathrm{C}_{\mathrm{N}}$ (acceptor on the whole) is compensated by the $\mathrm{H}$ atom (donor on the whole). In addition, this $\mathrm{C}_{\mathrm{N}}-\mathrm{H}_{\mathrm{I}}$ complex has a lower formation energy than $\mathrm{C}_{\mathrm{N}}-\mathrm{C}_{\mathrm{Ga}}$ complex, which is the most stable complex formed by two carbons in the $n$-type region ${ }^{5}$, by more than $2 \mathrm{eV}(3 \mathrm{eV})$ in N-rich (Ga-rich) conditions. Both in the $1+$ and the 0 (neutral) charged cases the most stable positions of $\mathrm{H}$ atom is the $\mathrm{AB}_{\perp}$ position. The distance between $\mathrm{C}$ and $\mathrm{H}$ is $1.10 \AA$ in both charge states. 


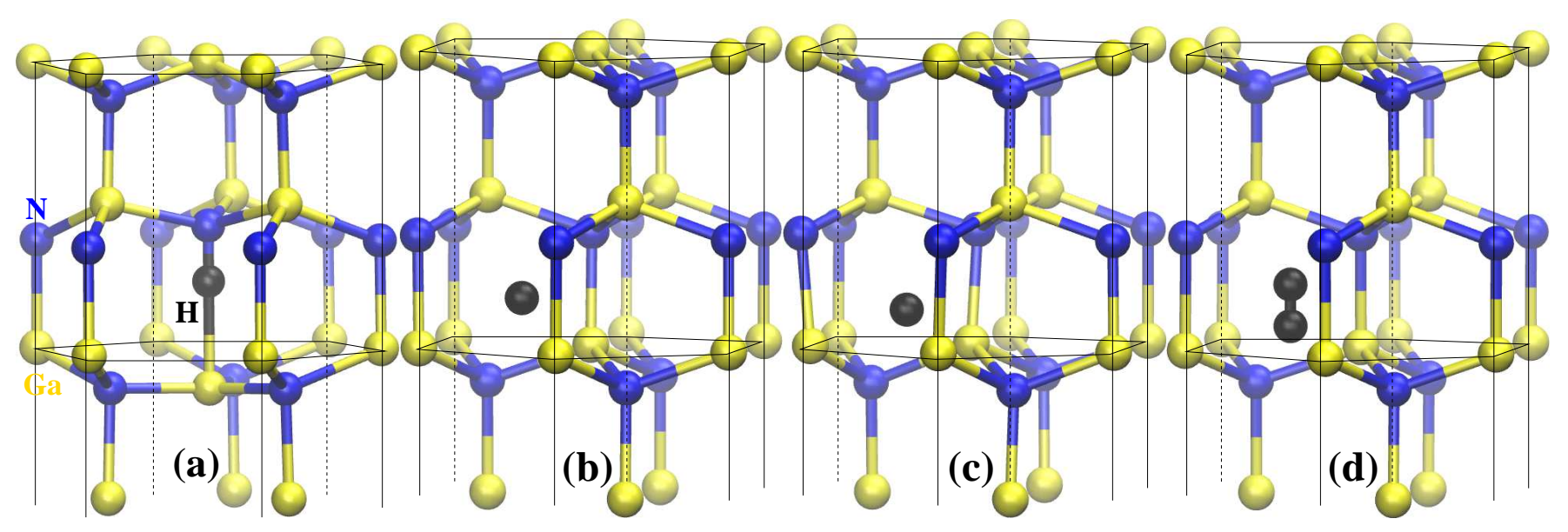

FIG. 1. Stable positions of $\mathrm{H}$ in GaN after relaxation in HSE. H atoms are denoted by black spheres, while Ga and N atoms are denoted by yellow and blue spheres, respectively. (a) $\mathrm{BC}_{\|}$position in the $1+$ charge state. (b) octahedral position in the 0 (neutral) charge state. (c) octahedral position in the $1-$ charge state. Also Stable position of $\mathrm{H}_{2}$ in the 0 charge state is provided in (d).

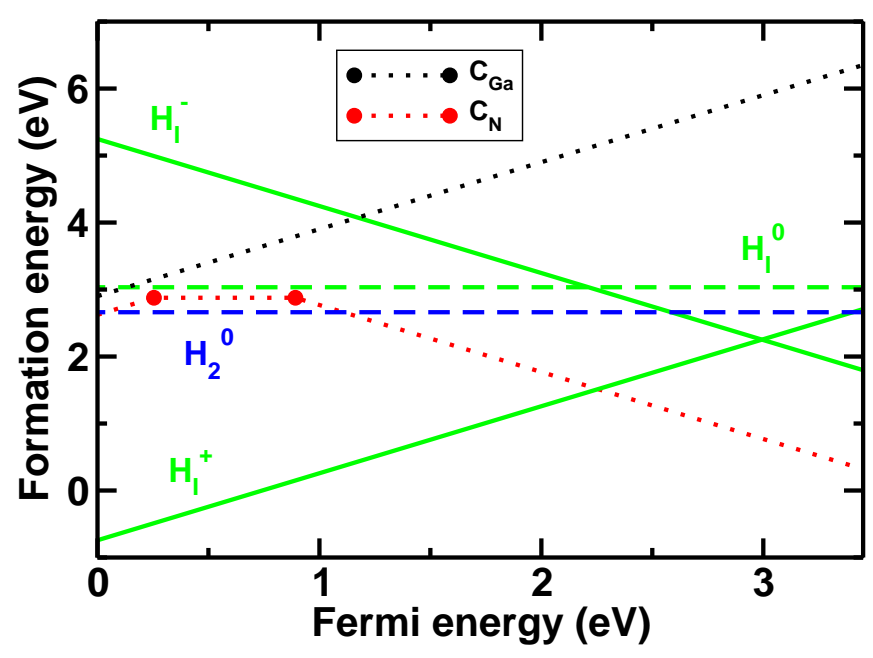

FIG. 2. Formation energies of $\mathrm{H}$ in $\mathrm{GaN}$ as a function of Fermi energy. Formation energies for $1+$ and 1 - charge states of $\mathrm{H}_{\mathrm{I}}$ are shown in green solid lines, whereas those for neutral $\mathrm{H}_{\mathrm{I}}$ and $\mathrm{H}_{2}$ are shown in green and blue dashed lines, respectively. The formation energies for $\mathrm{C}_{\mathrm{Ga}}$ and $\mathrm{C}_{\mathrm{N}}$ in Ga-rich conditions are also given as references in black and red dotted lines, respectively.

The structure is shown in FIG. 4 (a). The calculated binding energy of this complex is plotted in FIG. 5 with green solid line. The binding energy is always positive with the value up to $1.27 \mathrm{eV}$. Close to both band edges the value drops less than $0.5 \mathrm{eV}$ and the complex becomes relatively unstable.

For the $\mathrm{C}_{\mathrm{Ga}}-\mathrm{H}_{\mathrm{I}}$ complex, the $2+$ charge state is the most stable when the Fermi energy is between 0 and $2.27 \mathrm{eV}$ above the VBM. The neutral charge state becomes the most stable above $2.27 \mathrm{eV}$. In the $n$-type region (upper half of the band gap) the $\mathrm{C}_{\mathrm{Ga}}-\mathrm{H}_{\mathrm{I}}$ complex has higher formation energy than the $\mathrm{C}_{\mathrm{N}}-\mathrm{H}_{\mathrm{I}}$ complex both in N-rich and Ga-rich conditions. Comparing to the $\mathrm{C}_{\mathrm{N}}-\mathrm{C}_{\mathrm{Ga}}$ complex, the $\mathrm{C}_{\mathrm{Ga}}-\mathrm{H}_{\mathrm{I}}$ complex has about $1 \mathrm{eV}$ lower formation energy in N-rich condition, while in Ga-rich condition the formation energies of these two complexes are almost the same. Unlike in the $\mathrm{C}_{\mathrm{N}}-\mathrm{H}_{\mathrm{I}}$ complex, the $\mathrm{H}$ atom takes the bond center positions: $\mathrm{BC}_{\perp}$ in case of the $2+$ charge state, and $\mathrm{BC}_{\|}$in case of the neutral charge state. Their structural forms are shown in FIGs. 4 (b) and (c), respectively. In the $\mathrm{BC}_{\perp}$ position, the distance between $\mathrm{H}$ and $\mathrm{C}$ is $1.85 \AA$, whereas that between $\mathrm{H}$ and the nearest neighbor $\mathrm{N}$ is $1.01 \AA$. In the $\mathrm{BC}_{\|}$position, the distance between $\mathrm{H}$ and $\mathrm{C}$ is $1.08 \AA$, whereas that between $\mathrm{H}$ and the nearest neighbor $\mathrm{N}$ is $1.71 \AA$. The binding energy of this complex, that is shown in FIG. 5 with red dashed line, is always positive and the value increases close to the CBM to more than $3 \mathrm{eV}$. It should be noted that in $p$-type GaN both $\mathrm{C}_{\mathrm{Ga}}$ and $\mathrm{H}_{\mathrm{I}}$ are positively charged and expected to repel each other. This may impede the formation of this complex.

\section{B. Silicon impurity}

In this section we present results obtained for silicon. First, silicon is studied as a single impurity form (both substitutional and interstitial). Subsequently, their complexes with carbon are considered.

\section{Single Silicon Impurity}

First we present the results obtained for single Si impurity in GaN. As in the case of carbon shown in Part I of our work ${ }^{5}$, we considered Si substituting gallium $\left(\mathrm{Si}_{\mathrm{Ga}}\right)$, Si substituting nitrogen $\left(\mathrm{Si}_{\mathrm{N}}\right)$ and interstitial $\mathrm{Si}\left(\mathrm{Si}_{\mathrm{I}}\right)$. The calculated formation energies, both in N-rich and Ga-rich conditions, are given in Fig. 6 . 

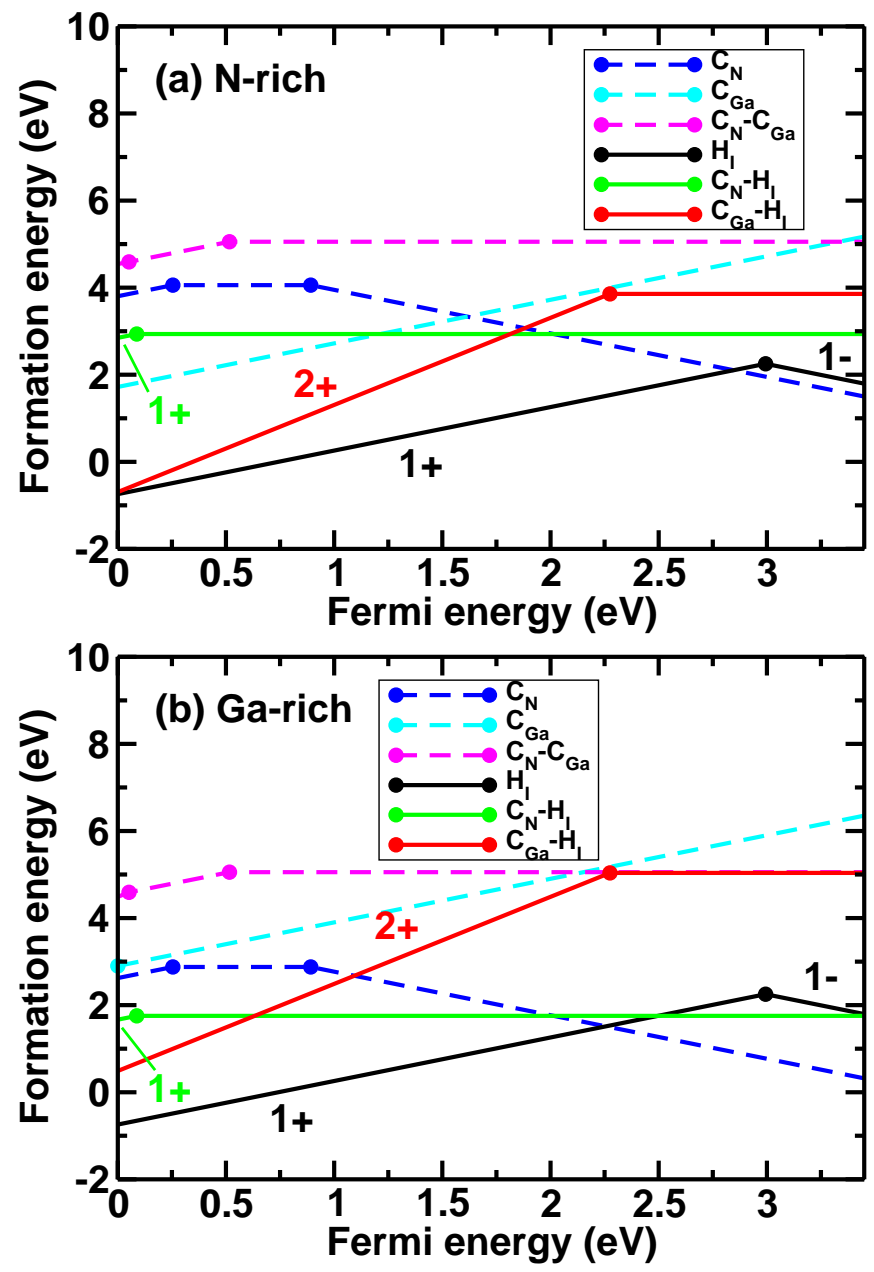

FIG. 3. Formation energies of $\mathrm{C}_{\mathrm{N}}-\mathrm{H}_{\mathrm{I}}$ (green solid line) and $\mathrm{C}_{\mathrm{Ga}}-\mathrm{H}_{\mathrm{I}}$ (red solid line) complexes in GaN as a function of Fermi energy (a) in N-rich and (b) in Ga-rich conditions. Formation energies for $\mathrm{C}_{\mathrm{N}}$ (blue dashed line), $\mathrm{C}_{\mathrm{Ga}}$ (cyan dashed line), $\mathrm{C}_{\mathrm{N}}-\mathrm{C}_{\mathrm{Ga}}$ (magenta dashed line) and $\mathrm{H}_{\mathrm{I}}$ (black solid line) are also given as references.

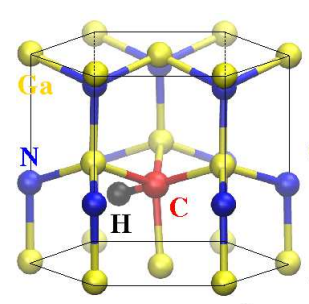

(a) $\mathrm{C}_{\mathrm{N}^{-}} \mathrm{H}_{\mathrm{I}}^{\mathbf{0}}$

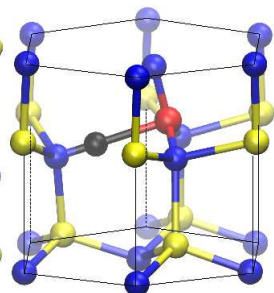

(b) $\mathrm{C}_{\mathrm{Ga}^{-}} \mathrm{H}_{\mathrm{I}}^{2+}$

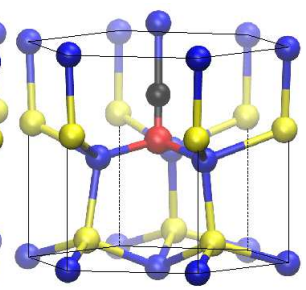

(c) $\mathrm{C}_{\mathrm{Ga}^{-}}-\mathrm{H}_{\mathrm{I}}^{\mathbf{0}}$
FIG. 4. (a) Stable position of $\mathrm{C}_{\mathrm{N}}-\mathrm{H}_{\mathrm{I}}$ complex in GaN after the relaxation by HSE. $\mathrm{H}$ atom is denoted by black sphere, while $\mathrm{C}$ atom is denoted by red sphere. $\mathrm{H}_{\mathrm{I}}$ is located at the $\mathrm{AB}_{\perp}$ position with $1.10 \AA$ distance from $\mathrm{C}_{\mathrm{N}}$. Stable positions of $\mathrm{C}_{\mathrm{Ga}}-\mathrm{H}_{\mathrm{I}}$ complex in the (b) $2+$ and (c) 0 charge states after the relaxation by HSE. In the $2+$ charge state, the complex is the most stable in the $\mathrm{BC}_{\perp}$ position with $\mathrm{C}-\mathrm{H}$ distance of $1.85 \AA$, while in the 0 charge state it is the most stable in the $\mathrm{BC}_{\|}$position with $\mathrm{C}-\mathrm{H}$ distance of $1.08 \AA$.

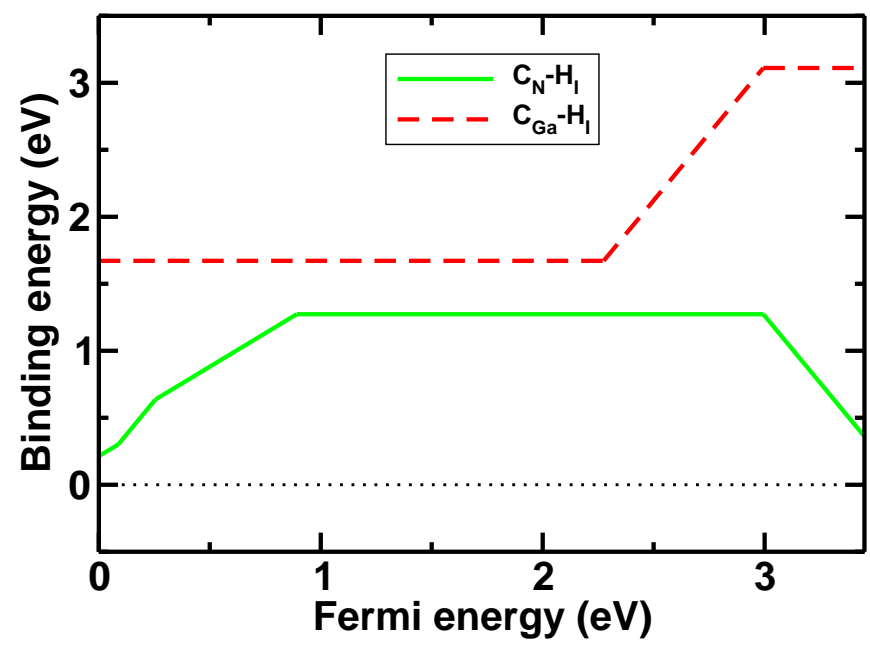

FIG. 5. The calculated binding energy for $\mathrm{C}_{\mathrm{N}}-\mathrm{H}_{\mathrm{I}}$ (green solid line) and $\mathrm{C}_{\mathrm{Ga}}-\mathrm{H}_{\mathrm{I}}$ (red dashed line) complexes as a function of Fermi energy.

For $\mathrm{Si}_{\mathrm{Ga}}$, the $1+$ charge state is the most stable within the entire band gap (black solid line in Fig. 6) and behaves as a shallow donor. This result is consistent with previous LDA-based calculations by different groups ${ }^{11,12,38}$. In this $\mathrm{Si}_{\mathrm{Ga}}^{1+}$ configuration, the neighboring $\mathrm{N}$ atoms around Si relax slightly inward. The average $\mathrm{Si}-\mathrm{N}$ bond length is $1.78 \AA$ ( 9 \% shorter than $\mathrm{Ga}-\mathrm{N}$ bond length).

$\mathrm{Si}_{\mathrm{N}}$ has significantly higher formation energy than $\mathrm{Si}_{\mathrm{Ga}}$ and shows amphoteric behavior with two transition levels around the middle of the band gap. The $(+/ 0)$ donor level appears at $1.39 \mathrm{eV}$ above the VBM and the $(0 /-)$ acceptor level appears at $2.05 \mathrm{eV}$ above the VBM. Because of the size difference between $\mathrm{Si}$ and $\mathrm{N}$, a larger lattice deformation is observed in contrast to the $\mathrm{Si}_{\mathrm{Ga}}$ case. The $\mathrm{Si}-\mathrm{Ga}$ bonds are elongated in all charge states and their average lengths for the $1+, 0,1-$ charge states are $2.29,2.24$ and $2.19 \AA$, respectively.

$\mathrm{Si}_{\text {I }}$ mostly behaves as a donor, but shows amphoteric behavior with the 1 - charge state being the most stable between $3.38 \mathrm{eV}$ above the VBM and the CBM. The 0 (neutral) charge state is the most stable between $3.12 \mathrm{eV}$ and $3.38 \mathrm{eV}$. From the VBM to $1.46 \mathrm{eV}$ above the VBM, the $4+$ charge state is the most stable, followed by the $3+$ charge states between $1.46 \mathrm{eV}$ and $1.81 \mathrm{eV}$. subsequently, the $2+$ charge state becomes the most stable between $1.81 \mathrm{eV}$ and $3.12 \mathrm{eV}$.

We considered the same starting configurations for $\mathrm{Si}_{\mathrm{I}}$ as those of $\mathrm{C}_{\mathrm{I}}{ }^{5}$, i.e. octahedral, tetrahedral, split and bond center positions. After full relaxations we found that $\mathrm{Si}_{\text {I }}$ takes only three stable configurations: tetrahedral $(4+)$, octahedral $(3+$ and $2+)$ and split type $2(0$ and 1-) interstitial configurations. These three configurations are shown in Fig. 7 . In the $4+$ charge state [Figs. 7 (a) and (b)], Si atom takes the tetrahedral interstitial position and has four bonds with surrounding $\mathrm{N}$ atoms (1.76 $\AA$ bond length on average). The near- 
est neighbor $\mathrm{Ga}$ atom is pushed by the $\mathrm{Si}$ atom to the hexagonal channel and takes the octahedral-like interstitial position. This movement is shown by the red arrow in Fig 7 (b). The distance between the pushed Ga and Si is $2.48 \AA$, whereas those between the Ga and surrounding three $\mathrm{N}$ atoms are $2.07 \AA$ on average. In the $3+$ and $2+$ charge states, Si atom takes the octahedral interstitial position, where $\mathrm{Si}$ atom is surrounded by three $\mathrm{N}$ atoms, as shown in Fig. 7 (c). The average bond length between $\mathrm{Si}$ and $\mathrm{N}$ atoms is $1.75 \AA$ and $1.81 \AA$ in the $3+$ and $2+$ charge states. In the 0 (neutral) and $1-$ charge states, Si atom takes the type-2 split interstitial configuration, where tilted $\mathrm{Si}-\mathrm{N}$ dimer replaces $\mathrm{N}$ atom and $\mathrm{N}$ is positioned higher than $\mathrm{Si}$ [see Fig. 7 (d)]. The $\mathrm{N}$ atom has two $\mathrm{Ga}-\mathrm{N}$ bonds perpendicular to the $c$-axis. The Si atom also has two bonds with $\mathrm{Ga}$, but one is parallel to the $c$-axis and the other is perpendicular to it. The average lengths of two $\mathrm{Ga}-\mathrm{N}$ bonds in the 0 and 1 - charge states are 1.90 and $1.87 \AA$, respectively. The $\mathrm{Si}-\mathrm{Ga}$ bonds in perpendicular and parallel directions are 2.18 and $2.21 \AA$ in the 0 charge state and 2.17 and $2.17 \AA$ in the 1 - charge state, respectively.

As a single impurity form of $\mathrm{Si}, \mathrm{Si}_{\mathrm{Ga}}$ is the dominant form, both in N-rich and Ga-rich conditions, with much lower formation energies than both $\mathrm{Si}_{\mathrm{N}}$ and $\mathrm{Si}_{\mathrm{I}}$. In particular, $\mathrm{Si}_{\mathrm{I}}$ has very high formation energy in the upper half of the band gap ( $n$-type region). Therefore, the next subsection of the manuscript will focus on the complexes involving $\mathrm{Si}_{\mathrm{Ga}}$ and $\mathrm{Si}_{\mathrm{N}}$.

\section{Complexes of Silicon with Carbon}

In this subsection we outline the results obtained for complexes made of $\mathrm{Si}$ and $\mathrm{C}$. First we deal with pairs of substitutional impurities, i.e. $\mathrm{Si}_{\mathrm{Ga}}-\mathrm{C}_{\mathrm{N}}$ and $\mathrm{Si}_{\mathrm{N}}-\mathrm{C}_{\mathrm{Ga}}$. Subsequently, we consider complexes made of substitutional-interstitial pairs, i.e. $\mathrm{Si}_{\mathrm{I}}-\mathrm{C}_{\mathrm{N}}$ and $\mathrm{Si}_{\mathrm{Ga}}-\mathrm{C}_{\mathrm{I}}$. The formation energies for these $\mathrm{Si}-\mathrm{C}$ complexes are shown in Fig. 8 both in (a) N-rich and (b) Ga-rich conditions.

There are two possible configurations for $\mathrm{Si}_{\mathrm{Ga}}-\mathrm{C}_{\mathrm{N}}$ and $\mathrm{Si}_{\mathrm{N}}-\mathrm{C}_{\mathrm{Ga}}$. In one configuration $\mathrm{Si}$ and $\mathrm{C}$ have a bond parallel to the $c$-axis (parallel configuration) and in the other configuration the bond is perpendicular to the $c$-axis (perpendicular configuration). These configurations are given in Fig. 9. In all the charge states except for $1+$ in the $\mathrm{Si}_{\mathrm{Ga}}-\mathrm{C}_{\mathrm{N}}$ complex, the perpendicular configuration has lower energy than the parallel configuration, but the energy difference is very small (up to $0.11 \mathrm{eV})$. The $\mathrm{Si}_{\mathrm{Ga}}-\mathrm{C}_{\mathrm{N}}$ complex has the lowest formation energy among them. In the very small region close to the VBM, the $1+$ charge state is favorable up to $0.27 \mathrm{eV}$ above the VBM. Above that energy, only the 0 (neutral) charge state becomes favorable throughout the band gap. This neutral charge states is a result of the compensation between $\mathrm{Si}_{\mathrm{Ga}}^{+}$and $\mathrm{C}_{\mathrm{N}}^{-}$. The $\mathrm{Si}-\mathrm{C}$ bond lengths in the $1+$ and 0 charge states are $1.85 \AA$ and $1.81 \AA$, respec-
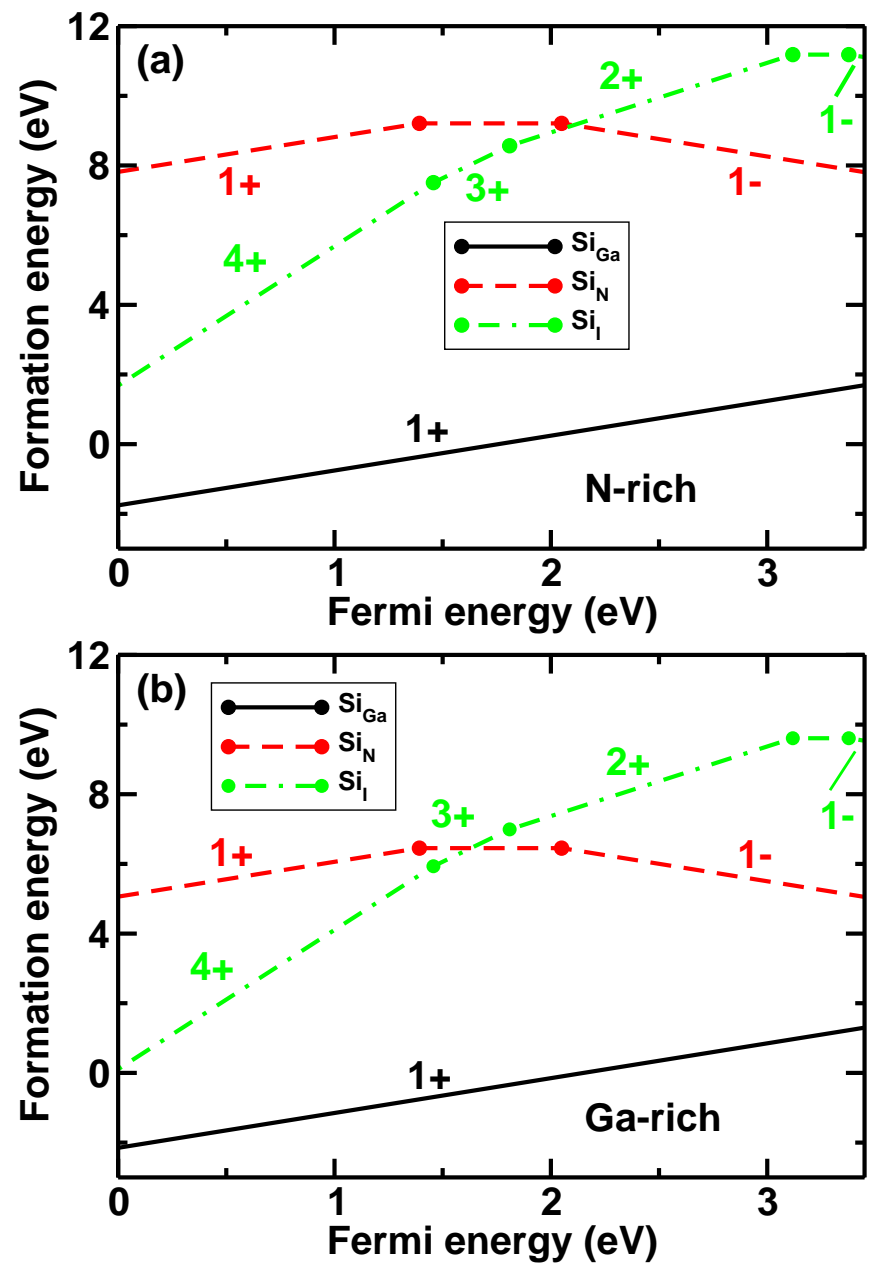

FIG. 6. Formation energies as a function of Fermi energy for $\mathrm{Si}_{\mathrm{Ga}}$ (black solid line), $\mathrm{Si}_{\mathrm{N}}$ (red dashed line) and $\mathrm{Si}_{\mathrm{I}}$ (green dashed-dotted line) in (a) N-rich and (b) Ga-rich conditions.

tively. The $\mathrm{Si}_{\mathrm{N}}-\mathrm{C}_{\mathrm{Ga}}$ complex has three charge states within the band gap. From the VBM to $0.68 \mathrm{eV}$ above the VBM, the $2+$ charge state is favorable. Then the $1+$ charge state becomes favorable between $0.68 \mathrm{eV}$ and $1.51 \mathrm{eV}$. Finally, the 0 (neutral) charge state becomes favorable in the rest of the band gap. The $\mathrm{Si}-\mathrm{C}$ bond lengths in the $2+, 1+$ and 0 charge states are $1.84 \AA$, $1.85 \AA$ and $1.86 \AA$, respectively.

$\mathrm{Si}_{\mathrm{I}}-\mathrm{C}_{\mathrm{N}}$ has three stable charge states within the band gap. The $3+$ charge state is the most stable between the VBM and $1.60 \mathrm{eV}$ above the VBM. Then between $1.60 \mathrm{eV}$ and $2.25 \mathrm{eV}$, the $2+$ charge state becomes the most stable. Finally the $1+$ charge state is most stable above $2.25 \mathrm{eV}$. Thus, this complex behaves as a shallow donor. In each charge state, the interstitial Si atom occupies the octahedral interstitial position located at the middle of the hexagonal channel, which is shown in Fig. 10. The $\mathrm{Si}-\mathrm{C}$ bond length is $1.75,1.80$ and $1.87 \AA$ in the $3+$, $2+$ and $1+$ charge states, respectively. The more positive charge state the complex takes, the shorter the bond length becomes. 


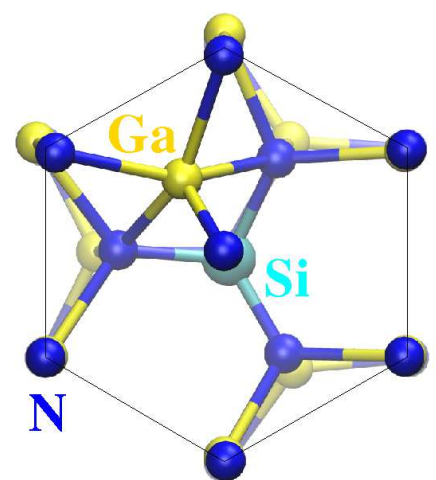

(a) $\mathrm{Si}_{\mathrm{I}}^{4+}$ top
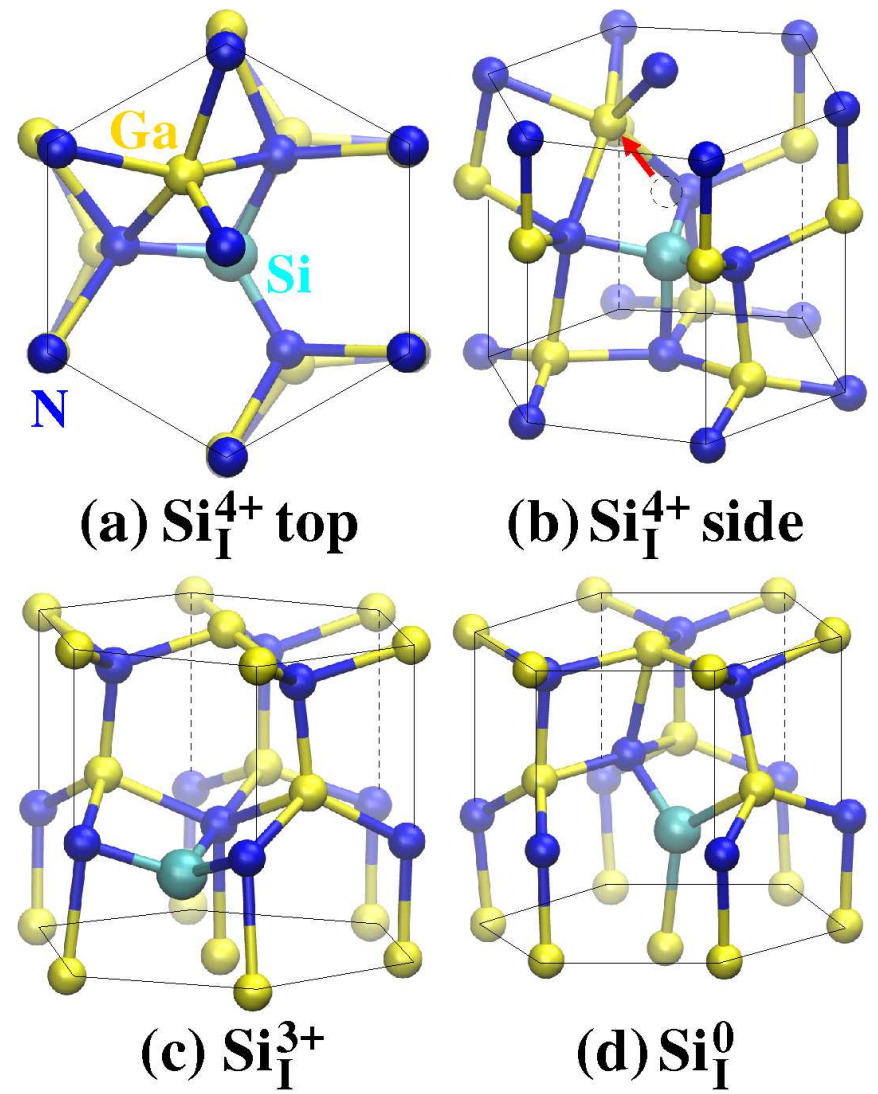

(b) $\mathrm{Si}_{\mathrm{I}}^{4+}$ side

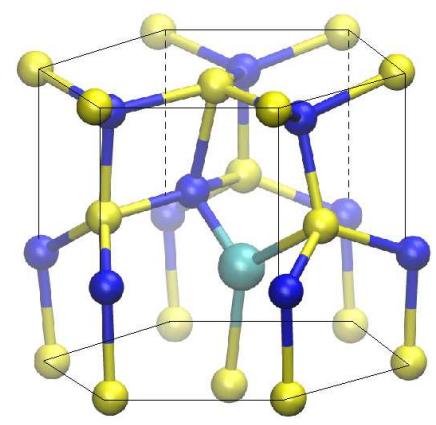

(d) $\mathbf{S i}_{\mathbf{I}}^{0}$

FIG. 7. Ball and stick representations of the stable configurations of $\mathrm{Si}_{I}$. Si atom is denoted by cyan sphere, while $\mathrm{Ga}$ and $\mathrm{N}$ are denoted by yellow and blue spheres, respectively. Fully relaxed (a) tetrahedral configuration with the $4+$ charge state from the top, (b) the same from the side, (c) octahedral configuration with the $3+$ charge state and (d) type 2 split interstitial configurations.

$\mathrm{Si}_{\mathrm{Ga}}-\mathrm{C}_{\mathrm{I}}$ complex takes three charge states within the band gap. When the Fermi energy is located between the VBM and $1.03 \mathrm{eV}$ above from the VBM, the complex takes the $3+$ charge states as the most stable form. Between $1.03 \mathrm{eV}$ and $1.71 \mathrm{eV}$ above the VBM, the $2+$ charge state is the most stable. Above $1.71 \mathrm{eV}$, the $1+$ charge state is the most stable up to $2.60 \mathrm{eV}$. Finally, the neutral charge state is the most stable above $2.60 \mathrm{eV}$. This complex acts as a deep donor. This complex takes two different configurations. In both configurations, $\mathrm{C}$ atom is located at the site next to $\mathrm{Si}_{\mathrm{Ga}}$ and forms a split interstitial with $\mathrm{N}$ atom, i.e. forming a $\mathrm{C}-\mathrm{N}$ dimer. In case of the $3+$ charge state, the $\mathrm{C}$ atom forms a type 3 split interstitial sharing the site with an $\mathrm{N}$ atom making a dimer, which is defined in Ref. 5. This configuration is shown in Fig. 11 (a). The distance between $\mathrm{Si}$ and $\mathrm{C}$ is $1.84 \AA$. In the other charge states, the $\mathrm{C}$ atom forms a type 1 split interstitial, which is shown in Fig. 11 (b). The distance between $\mathrm{Si}$ and $\mathrm{C}$ is $1.86 \AA, 1.79 \AA$ and $1.78 \AA$ for the $2+$, $1+$ and 0 (neutral) charge states, respectively.

The binding energies for these four different siliconbased complexes are shown in Fig. 12. For the $\mathrm{Si}_{\mathrm{Ga}}-\mathrm{C}_{\mathrm{N}}$
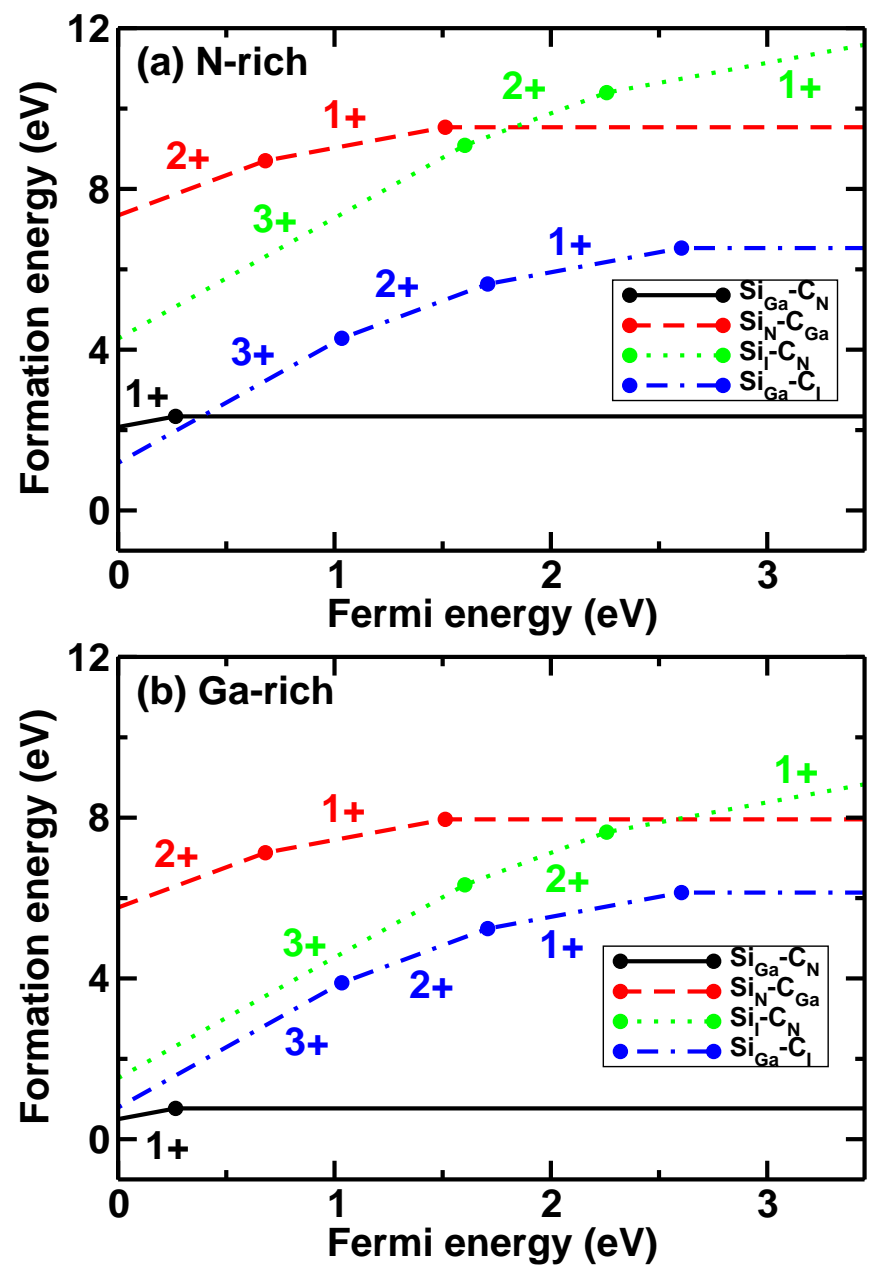

FIG. 8. Formation energies as a function of Fermi energy both in (a) N-rich and (b) Ga-rich conditions for $\mathrm{Si}-\mathrm{C}$ complexes: $\mathrm{Si}_{\mathrm{Ga}}-\mathrm{C}_{\mathrm{N}}$ in black solid line, $\mathrm{Si}_{\mathrm{N}}-\mathrm{C}_{\mathrm{Ga}}$ in red dashed line, $\mathrm{Si}_{\mathrm{I}}-\mathrm{C}_{\mathrm{N}}$ in green dotted line and $\mathrm{Si}_{\mathrm{Ga}}-\mathrm{C}_{\mathrm{I}}$ in blue dasheddotted line.

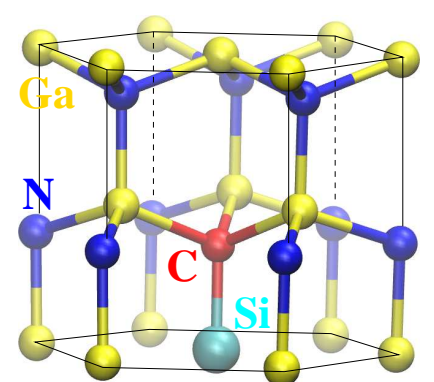

(a) parallel

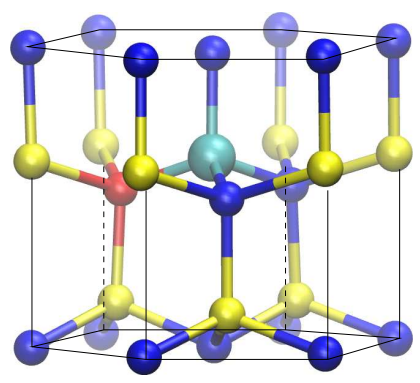

(b) perpendicular
FIG. 9. (a) Parallel and (b) perpendicular configurations of $\mathrm{Si}-\mathrm{C}$ complex in the case of $\mathrm{Si}_{\mathrm{Ga}}-\mathrm{C}_{\mathrm{N}}$. Si atom is denoted by cyan sphere, whereas $\mathrm{C}$ atom is denoted by red sphere. 

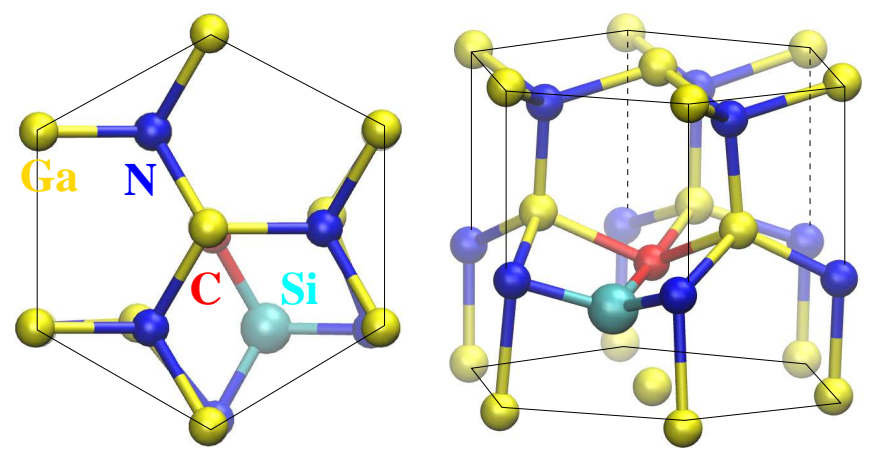

\section{(a) $\mathrm{Si}_{\mathrm{I}}-\mathrm{C}_{\mathrm{N}}$ top (b) $\mathrm{Si}_{\mathrm{I}}-\mathrm{C}_{\mathrm{N}}$ side}

FIG. 10. Relaxed structure for $\mathrm{Si}_{I}-\mathrm{C}_{\mathrm{N}}$ complex: (a) top view and (b) side view. Si atom is denoted by cyan sphere, whereas $\mathrm{C}$ atom is denoted by red sphere.
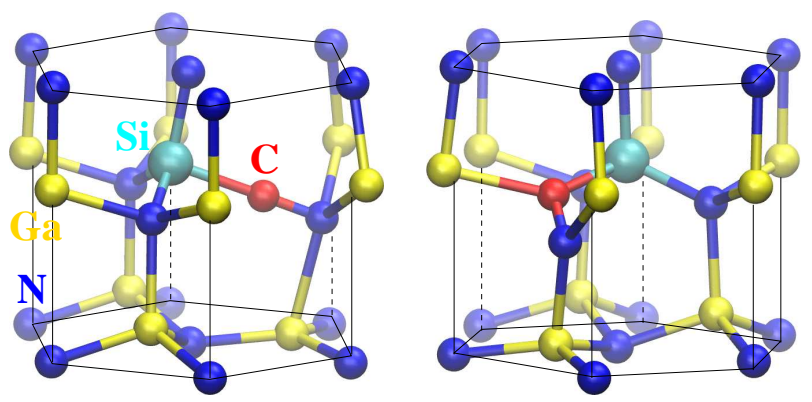

\section{(a) $\mathrm{Si}_{\mathrm{Ga}}-\mathrm{C}_{\mathrm{I}}$ type 3 (b) $\mathrm{Si}_{\mathrm{Ga}}-\mathrm{C}_{\mathrm{I}}$ type 1}

FIG. 11. Relaxed structure for $\mathrm{Si}_{\mathrm{Ga}}-\mathrm{C}_{\mathrm{N}}$ complex: (a) $\mathrm{C}_{I}$ forms a type 3 split interstitial with $\mathrm{N}$ at the site next to $\mathrm{Si}_{\mathrm{Ga}}$ and (b) $\mathrm{C}_{\mathrm{I}}$ forms a type 1 split interstitial with $\mathrm{N}$ at the site next to $\mathrm{Si}_{\mathrm{Ga}}$.

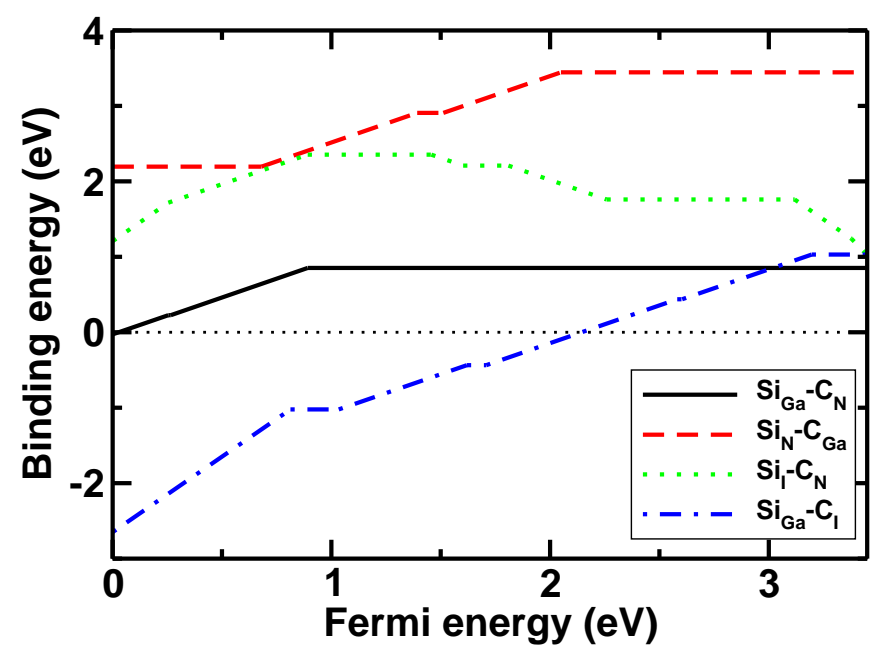

FIG. 12. Binding energies as a function of Fermi energy for $\mathrm{Si}_{\mathrm{Ga}}-\mathrm{C}_{\mathrm{N}}$ (black solid line), $\mathrm{Si}_{\mathrm{N}}-\mathrm{C}_{\mathrm{Ga}}$ (red dashed line), $\mathrm{Si}_{\mathrm{I}}-\mathrm{C}_{\mathrm{N}}$ (green dotted line) and $\mathrm{Si}_{\mathrm{Ga}}-\mathrm{C}_{\mathrm{I}}$ (blue dasheddotted line). complex (black solid line), the binding energy is negative or small when the Fermi energy is very close to the VBM. Thus the complex is unstable in $p$-type GaN. However, the binding energy becomes $0.85 \mathrm{eV}$ when the Fermi energy is $0.89 \mathrm{eV}$ or above. Thus the complex is expected to be stable in $n$-type $\mathrm{GaN}$. The $\mathrm{Si}_{\mathrm{N}}-\mathrm{C}_{\mathrm{Ga}}$ complex shows the highest value of the binding energy (dashed red line) among the four complexes with at least $2 \mathrm{eV}$ and up to $3.45 \mathrm{eV}$ near the CBM. The $\mathrm{Si}_{\mathrm{I}}-\mathrm{C}_{\mathrm{N}}$ complex also shows the positive binding energy with at least $1 \mathrm{eV}$ value. Finally, the $\mathrm{Si}_{\mathrm{Ga}}-\mathrm{C}_{\mathrm{I}}$ complex shows different behavior than other three complexes. When the Fermi energy is below $2.14 \mathrm{eV}$, the binding energy is negative. This implies that the $3+$ and the $2+$ charge states are unstable as a complex. Then the binding energy increases and reaches $1.03 \mathrm{eV}$ at the CBM.

\section{Oxygen Impurity}

\section{Single Oxygen Impurity}

As in the case of carbon and silicon, we considered three different types of single oxygen impurity, i.e. O substituting $\mathrm{Ga}\left(\mathrm{O}_{\mathrm{Ga}}\right)$, O substituting $\mathrm{N}\left(\mathrm{O}_{\mathrm{N}}\right)$ and interstitial $\mathrm{O}\left(\mathrm{O}_{\mathrm{I}}\right)$. We present the formation energies of each case in Fig. 13.

$\mathrm{O}_{\mathrm{N}}$ acts as a shallow donor with the $1+$ charge state being most stable configuration with energy level within the band gap. Its formation energy is very close to that of $\mathrm{Si}_{\mathrm{Ga}}$ and about $3 \sim 5 \mathrm{eV}$ lower than that of $\mathrm{C}_{\mathrm{Ga}}$. The $\mathrm{O}-$ Ga bond lengths (2.03 $\AA$ on average) are slightly longer than the $\mathrm{Ga}-\mathrm{N}$ bonds of bulk GaN.

In the case of $\mathrm{O}_{\mathrm{Ga}}$, the $2+$ charge state is the most stable up to $1.026 \mathrm{eV}$ above the VBM. In the very small range (from $1.026 \mathrm{eV}$ to $1.031 \mathrm{eV}$ from the $\mathrm{VBM}$ ), the $1+$ charge state is the most stable, before the 0 (neutral) charge state becomes the most stable between $1.031 \mathrm{eV}$ and $2.32 \mathrm{eV}$. Finally above $2.32 \mathrm{eV}$, the $3-$ charge state becomes the most stable state up to the CBM. In all above mentioned charge states, $\mathrm{O}$ atom is not located at the Ga atom site, but slightly displaced, making a bond with one of surrounding $\mathrm{N}$ atoms. This structure is consistent with the previously reported $\mathrm{O}_{\mathrm{Ga}}$ structure optimized within GGA calculations ${ }^{39}$. The structures are similar in the $2+, 1+$ and 0 charge states, where the $\mathrm{O}$ atom is displaced by about $0.67 \AA$ (on average) from the $\mathrm{Ga}$ site and forms a bond with one of surrounding $\mathrm{N}$ atom with $1.26 \AA$ (on average) bond length. As a representative case, the structure in the 0 charge state is given in Fig. 14(a). The structure in the 3- charge state is different from the ones in other charge states. The $\mathrm{O}$ atom is more displaced from the Ga site $(1.46 \AA)$. It is positioned above the Ga-layer and forms an $\mathrm{O}-\mathrm{N}$ bond with $1.46 \AA$ length. In addition, it pushes up an $\mathrm{N}$ atom located at the other side of the $\mathrm{O}-\mathrm{N}$ bond [see Fig. 14 (b)], and the pushed N atom is located at Ga-layer.

Three charge states are observed within the band gap 

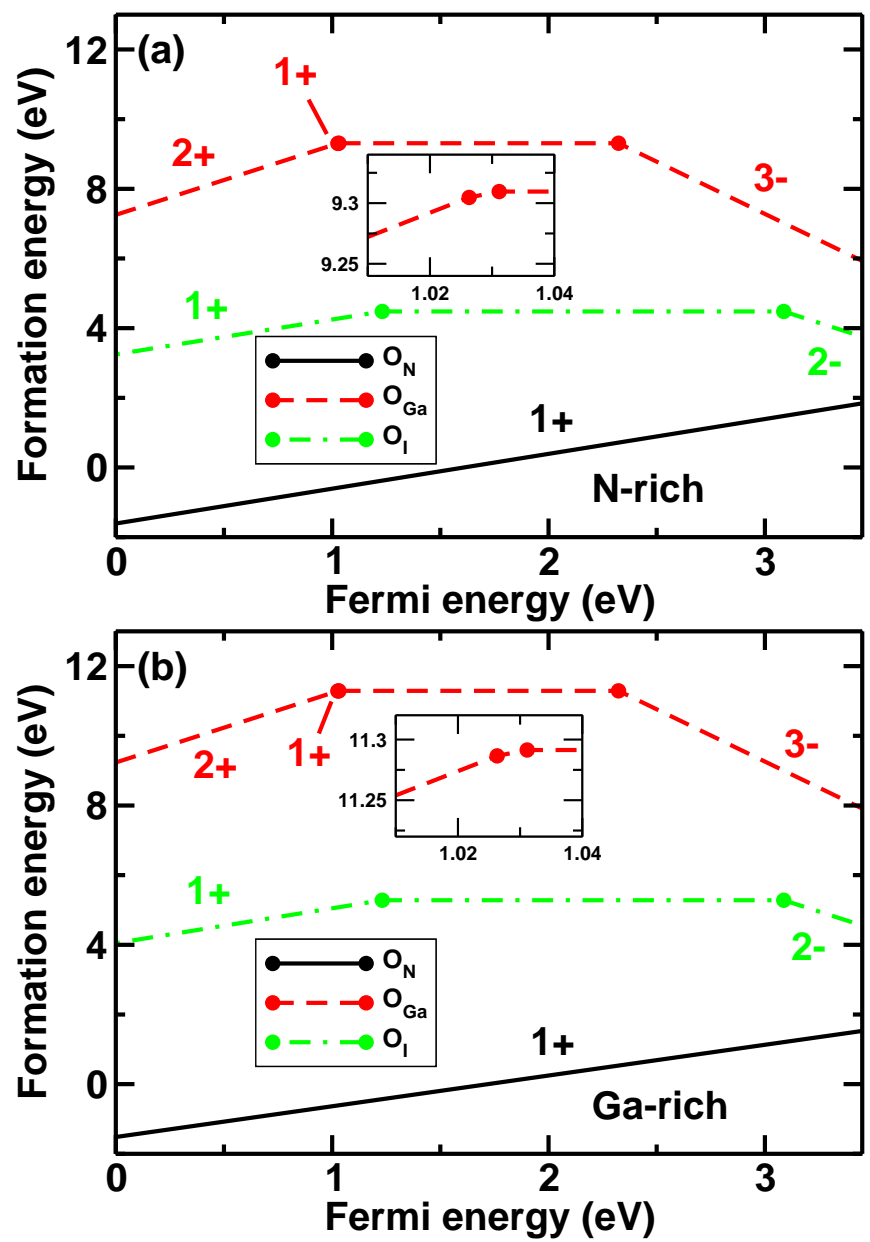

FIG. 13. Formation energies as a function of Fermi energy for $\mathrm{O}_{\mathrm{N}}$ (black solid line), $\mathrm{O}_{\mathrm{Ga}}$ (red dashed line) and $\mathrm{O}_{\mathrm{I}}$ (green dashed-dotted line) in (a) N-rich and (b) Ga-rich conditions. The insets are to show the appearance of the $1+$ charge state in the very narrow region in the case of $\mathrm{O}_{\mathrm{Ga}}$.

as stable configurations for $\mathrm{O}_{\mathrm{I}}$. The $1+$ charge state is the most stable up to $1.23 \mathrm{eV}$ above the VBM. Then the neutral charge state becomes the most stable up to $3.09 \mathrm{eV}$. Finally the $2-$ charge state is the most stable between $3.09 \mathrm{eV}$ and the CBM. In the $1+$ and neutral charge states, $\mathrm{O}$ atom forms a split interstitial with a $\mathrm{N}$ atom. The structure for the $1+$ charge state is shown in Fig. 15 (a). The distance between $\mathrm{O}$ and $\mathrm{N}$ atom is $1.33 \AA$ in the $1+$ charge state and $1.43 \AA$ in the neutral charge state, respectively. In the $2-$ charge state, $\mathrm{O}$ atoms is located at an octahedral interstitial position, as shown in Fig. 15 (b). The interstitial $\mathrm{O}$ atom has bonds with three surrounding $\mathrm{Ga}$ atoms with equivalent distances of $1.88 \AA$.

\section{Complexes of Oxygen with Carbon}

As in the case of silicon, we show the results obtained for complexes composed of $\mathrm{O}$ and $\mathrm{C}$. The complexes we
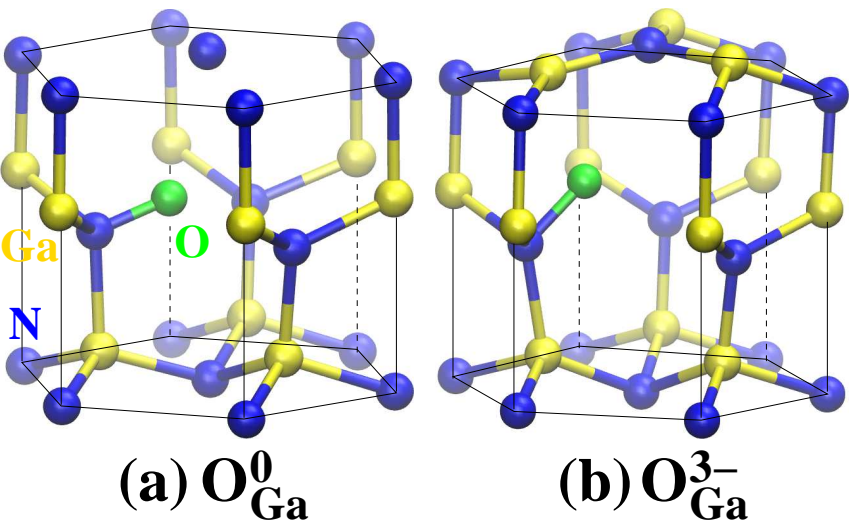

FIG. 14. Ball and stick representation of the relaxed $\mathrm{O}_{\mathrm{Ga}}$ structures in (a) 0 (neutral) charge state and (b) 3- charge state. $\mathrm{O}$ atom is denoted by green sphere, while Ga and $\mathrm{N}$ atoms are denoted by yellow and blue spheres, respectively.
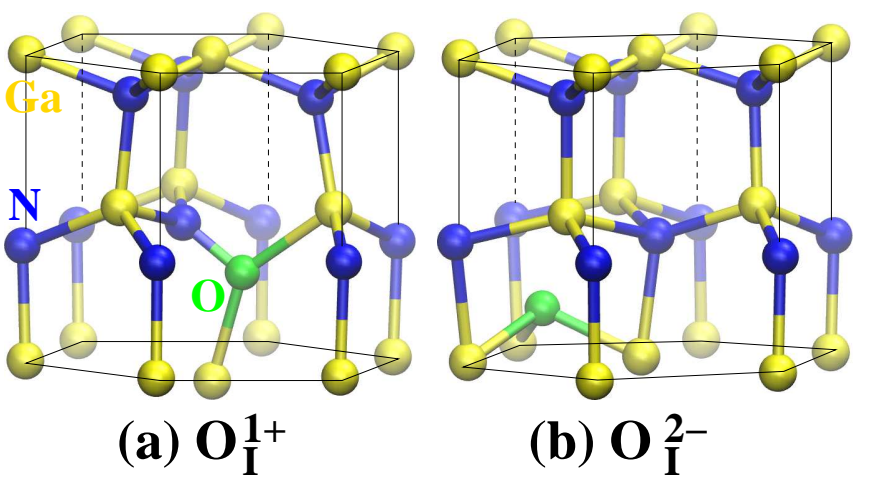

FIG. 15. Ball and stick representation of the relaxed $\mathrm{O}_{\mathrm{I}}$ structures in the (a) $1+$ charge state and (b) 2- charge state. O atom is denoted by green sphere, while $\mathrm{Ga}$ and $\mathrm{N}$ atoms are denoted by yellow and blue spheres, respectively.

consider here are pairs of substitutional impurities, i.e. $\mathrm{O}_{\mathrm{N}}-\mathrm{C}_{\mathrm{Ga}}$ and $\mathrm{O}_{\mathrm{Ga}}-\mathrm{C}_{\mathrm{N}}$. We also examine complexes made of substitutional-interstitial pairs, i.e. $\mathrm{O}_{\mathrm{I}}-\mathrm{C}_{\mathrm{N}}$ and $\mathrm{O}_{\mathrm{N}}-\mathrm{C}_{\mathrm{I}}$, which, eventually, relax into the same structure $\left(\mathrm{O}_{\mathrm{I}}-\mathrm{C}_{\mathrm{N}}\right)$ after the full geometry optimizations. In addition to them, $\mathrm{O}_{\mathrm{N}}-\mathrm{C}_{\mathrm{N}}$ complexes are also taken into account. In this last complex, the oxygen and carbon constituents, $\mathrm{O}_{\mathrm{N}}$ and $\mathrm{C}_{\mathrm{N}}$, are located as a second nearest neighbor. This is an exceptional case, because we have limited ourselves to consider only nearest neighbor pairs for the constituents of complexes in all cases shown so far. Recently this complex has been extensively studied by several groups due to the realization that it could be the origin of the yellow luminescence phenomena ${ }^{13,14,19}$. As a result, we decided to include it as a potential candidate for carbon related impurities which induce trap levels within the band gap. The formation energies for above-mentioned $\mathrm{O}-\mathrm{C}$ complexes are shown in Fig. 16 both in (a) N-rich and (b) Ga-rich conditions.

In the case of $\mathrm{O}_{\mathrm{N}}-\mathrm{C}_{\mathrm{Ga}}$, the $2+$ and the $1+$ charge states are stable with energy levels within the band gap. 

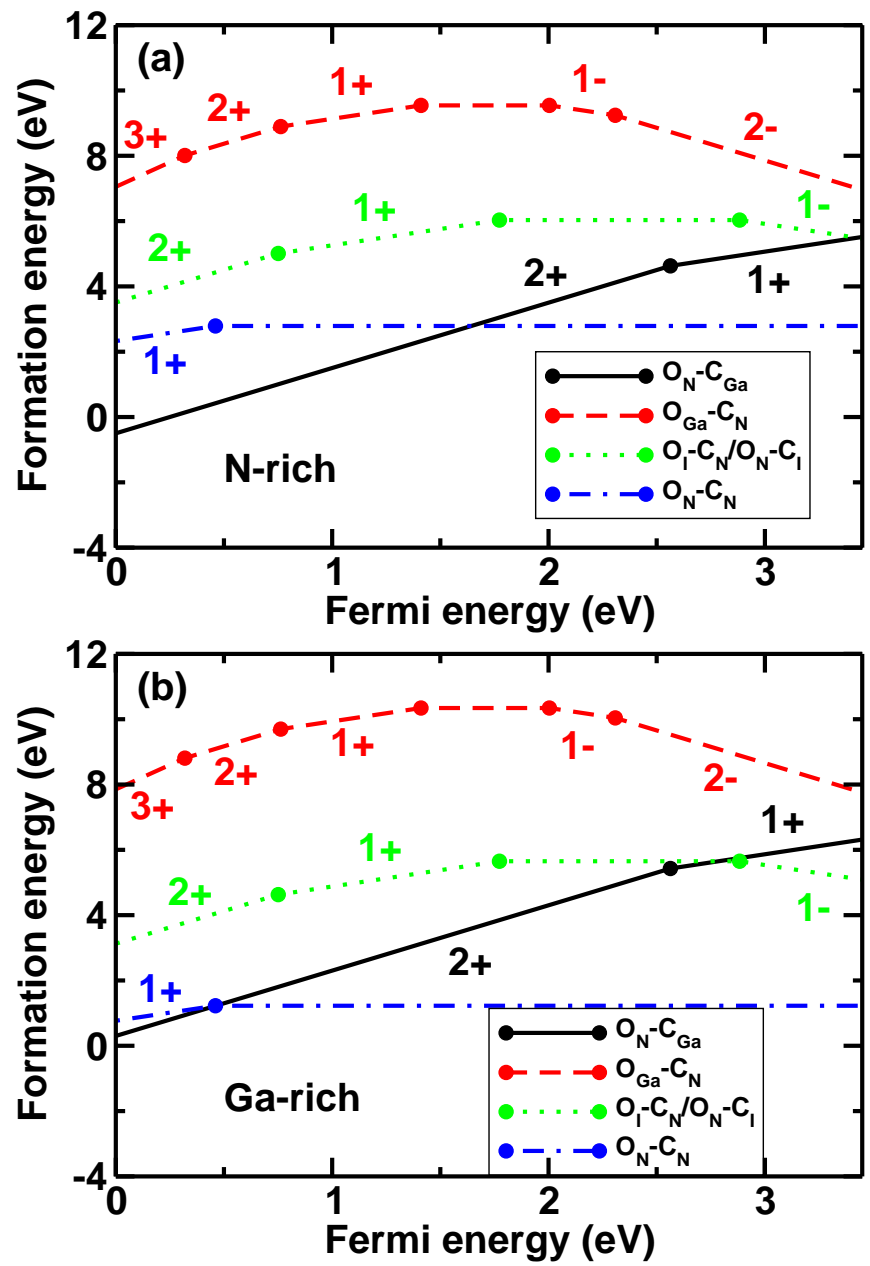

FIG. 16. Formation energies as a function of Fermi energy for $\mathrm{O}_{\mathrm{N}}-\mathrm{C}_{\mathrm{Ga}}$ (black solid line), $\mathrm{O}_{\mathrm{Ga}}-\mathrm{C}_{\mathrm{N}}$ (red dashed line), $\mathrm{O}_{\mathrm{I}}-\mathrm{C}_{\mathrm{N}} / \mathrm{O}_{\mathrm{N}}-\mathrm{C}_{\mathrm{I}}$ (green dotted line) and $\mathrm{O}_{\mathrm{N}}-\mathrm{C}_{\mathrm{N}}$ (blue dashed-dotted line) in (a) N-rich and (b) Ga-rich conditions.

The $2+$ charge state is stable up to $2.56 \mathrm{eV}$ above the VBM. Above $2.56 \mathrm{eV}$ the $1+$ charge state becomes stable. Both parallel and perpendicular configurations are considered and the perpendicular configuration has slightly lower energies (at most $0.1 \mathrm{eV}$ ) than the parallel configuration in both charge states. This complex has relatively low formation energy particularly close to the VBM. However, both $\mathrm{O}_{\mathrm{N}}$ and $\mathrm{C}_{\mathrm{Ga}}$ are shallow donors and exist only with positively charged states. Thus, they are expected to repel each other under any conditions and $\mathrm{O}_{\mathrm{N}}-\mathrm{C}_{\mathrm{Ga}}$ complex is unlikely to be formed despite its low formation energy.

$\mathrm{O}_{\mathrm{Ga}}-\mathrm{C}_{\mathrm{N}}$ complex takes six different charge states from the values $3+$ to $2-$. The $3+$ charge state is stable up to $0.32 \mathrm{eV}$ above the VBM. Between $0.32 \mathrm{eV}$ and $0.76 \mathrm{eV}$, the $2+$ charge state becomes stable. Then the stable charge state is changed to $1+$ between $0.76 \mathrm{eV}$ and $1.41 \mathrm{eV}$. The neutral and $1-$ charge states are favorable between $1.41 \mathrm{eV}$ and $2.00 \mathrm{eV}$ and between $2.00 \mathrm{eV}$ and $2.31 \mathrm{eV}$, respectively. Finally the $2-$ state becomes sta-

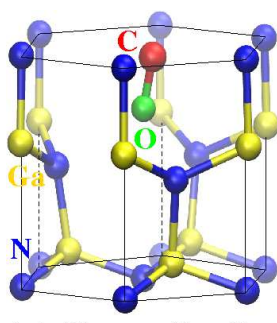

(a) $\mathrm{O}_{\mathrm{Ga}}-\mathrm{C}_{\mathrm{N}} 2+$

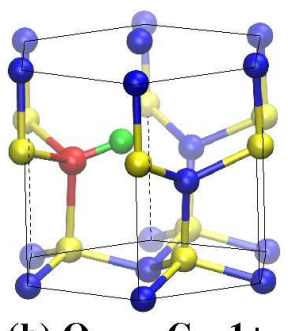

(b) $\mathrm{O}_{\mathrm{Ga}}-\mathrm{C}_{\mathrm{N}} 1+$

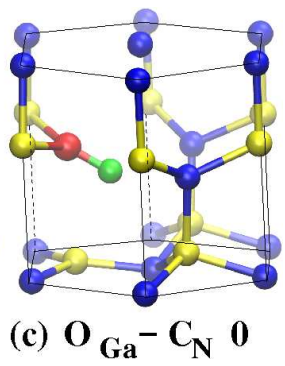

FIG. 17. Ball and stick representation of the relaxed $\mathrm{O}_{\mathrm{Ga}}-\mathrm{C}_{\mathrm{N}}$ structures: (a) $2+$ charge state in the parallel configuration, (b) $1+$ charge state in the perpendicular configuration and (c) 0 charge state in the perpendicular configuration. $\mathrm{O}$ and $\mathrm{C}$ atoms are denoted by green and red spheres, respectively, while $\mathrm{Ga}$ and $\mathrm{N}$ atoms are denoted by yellow and blue spheres, respectively.

ble above $2.31 \mathrm{eV}$. The perpendicular configuration has lower energy than the parallel configuration in all charge states except for the $2+$ case (the difference is less than $30 \mathrm{meV}$ in this charge state, though). The parallel configuration in the 2+ charge state is shown in Fig. 17(a). $\mathrm{O}_{\mathrm{Ga}}$ is slightly displaced from the Ga site and is located closer to the $\mathrm{C}$ atom, which is located at the $\mathrm{N}$ site. The $\mathrm{O}-\mathrm{C}$ distance is $1.18 \AA$. In the perpendicular configuration, $\mathrm{O}$ and $\mathrm{C}$ atoms take similar positions in the $3+$, $1+, 1-$ and $2-$ charge states. This configuration with the $1+$ charge state is shown in Fig. 17 (b) as a representative case. In this case, $\mathrm{C}$ atom stays at the $\mathrm{N}$ site, while the $\mathrm{O}$ atom is displaced from the Ga site toward $\mathrm{C}$ atom. The $\mathrm{O}-\mathrm{C}$ distances are $1.13,1.24,1.20$ and $1.26 \AA$ in the $3+, 1+, 1-$ and $2-$ charge states, respectively. In the 0 charge state, both $\mathrm{O}$ and $\mathrm{C}$ atoms are displaced, which is shown in Fig. 17 (c). C atom is displaced slightly above the $\mathrm{N}$ site and $\mathrm{O}$ atom is displaced from the $\mathrm{Ga}$ site toward $\mathrm{C}$ site and is located below the Ga site. As a result, $\mathrm{C}$ atom is located higher position than $\mathrm{O}$ atom. The $\mathrm{O}-\mathrm{C}$ distance is $1.18 \AA$.

As already mentioned above, the $\mathrm{O}_{\mathrm{I}}-\mathrm{C}_{\mathrm{N}}$ and $\mathrm{O}_{\mathrm{N}}-\mathrm{C}_{\mathrm{I}}$ complexes relax into the same structure. The resulting complex takes the $2+, 1+, 0$ and $1-$ charge states. The $2+$ and $1-$ charge states are favorable between the VBM and $0.73 \mathrm{eV}$ and between $2.88 \mathrm{eV}$ and the CBM, respectively. The $1+$ charge state is stable between $0.73 \mathrm{eV}$ and $1.78 \mathrm{eV}$ whereas the neutral charge state is stable between $1.78 \mathrm{eV}$ and $2.88 \mathrm{eV}$. In all charge states, the $\mathrm{C}$ and $\mathrm{O}$ atoms form a dimer. The $\mathrm{C}$ atom always takes higher position than the $\mathrm{O}$ atom. The structure is shown in Fig. 18. The $\mathrm{O}-\mathrm{C}$ distances are 1.20, 1.28, 1.37 and $1.42 \AA$ for $2+, 1+, 0$ and $1-$ charge states, respectively.

Finally, we consider $\mathrm{O}_{\mathrm{N}}-\mathrm{C}_{\mathrm{N}}$ complex. In this complex, $\mathrm{O}$ and $\mathrm{C}$ are the second nearest neighbors to each other and two different configurations are investigated. One is the parallel configuration, where the $\mathrm{O}$ and $\mathrm{C}$ atoms are in the different N-plane, and the other is the perpendicular configuration, where the $\mathrm{O}$ and $\mathrm{C}$ atoms 


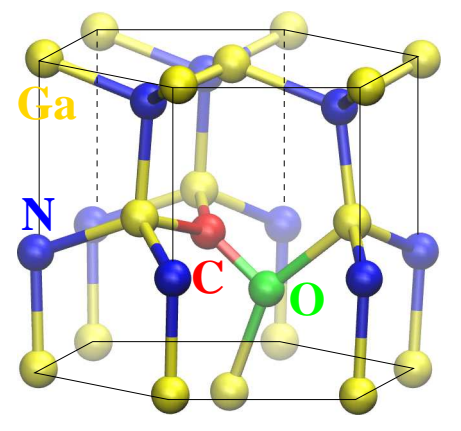

FIG. 18. Ball and stick representation of the relaxed $\mathrm{O}_{\mathrm{I}}-\mathrm{C}_{\mathrm{N}} / \mathrm{O}_{\mathrm{N}}-\mathrm{C}_{\mathrm{I}}$ structure in the 0 charge state. $\mathrm{O}$ and $\mathrm{C}$ atoms are denoted by green and red spheres, respectively, while $\mathrm{Ga}$ and $\mathrm{N}$ atoms are denoted by yellow and blue spheres, respectively.

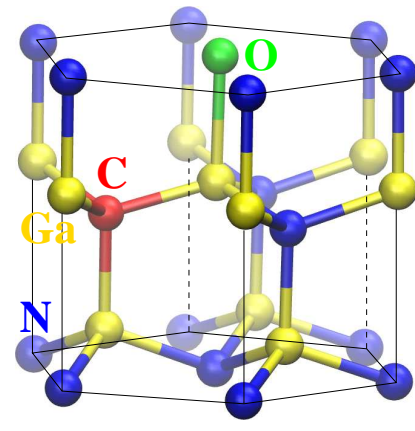

(a) parallel

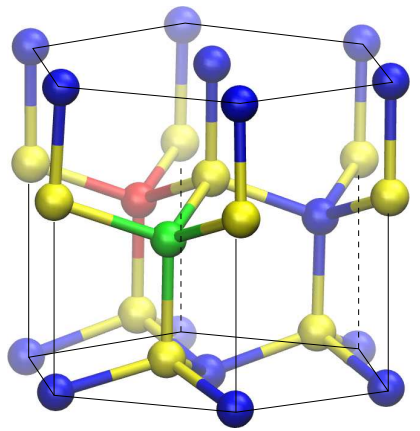

(b) perpendicular
FIG. 19. Ball and stick representation of the relaxed $\mathrm{O}_{N}-\mathrm{C}_{N}$ structures with the 0 charge states in (a) parallel and (b) perpendicular configurations. $\mathrm{O}$ and $\mathrm{C}$ atoms are denoted by green and red spheres, respectively, while Ga and $\mathrm{N}$ atoms are denoted by yellow and blue spheres, respectively. Note that $\mathrm{O}$ and $\mathrm{C}$ atoms are second nearest neighbors to each other in this complex.

are in the same N-plane. These two configurations are shown in Fig. 19 (a) and (b), respectively. The two configurations have almost the same energy after the geometry optimizations, but the perpendicular configurations always have slightly lower energy (less than $10 \mathrm{meV}$ difference) than the parallel configurations in all charge states. As shown in Fig. 16, this complex takes $1+$ and 0 charge states with the $(+/ 0)$ transition level at $0.46 \mathrm{eV}$. The distance between $\mathrm{O}$ and $\mathrm{C}$ are 3.20 and $3.22 \AA$ for the $1+$ and 0 charge states, respectively.

The binding energies for oxygen-carbon complexes studied in this section are given in Fig. 20. The $\mathrm{O}_{\mathrm{N}}-\mathrm{C}_{\mathrm{Ga}}$ and $\mathrm{O}_{\mathrm{N}}-\mathrm{C}_{\mathrm{N}}$ complexes have low binding energies. These low binding energies values for these complexes are expected. In the case of $\mathrm{O}_{\mathrm{N}}-\mathrm{C}_{\mathrm{Ga}}$, as mentioned above, both $\mathrm{O}_{\mathrm{N}}$ and $\mathrm{C}_{\mathrm{Ga}}$ act as shallow donors and they are expected to repel each other. As for the $\mathrm{O}_{\mathrm{N}}-\mathrm{C}_{\mathrm{N}}$ complex, $\mathrm{O}_{\mathrm{N}}$ and $\mathrm{C}_{\mathrm{N}}$ are second nearest neighbors, thus the binding is expected to be weaker than

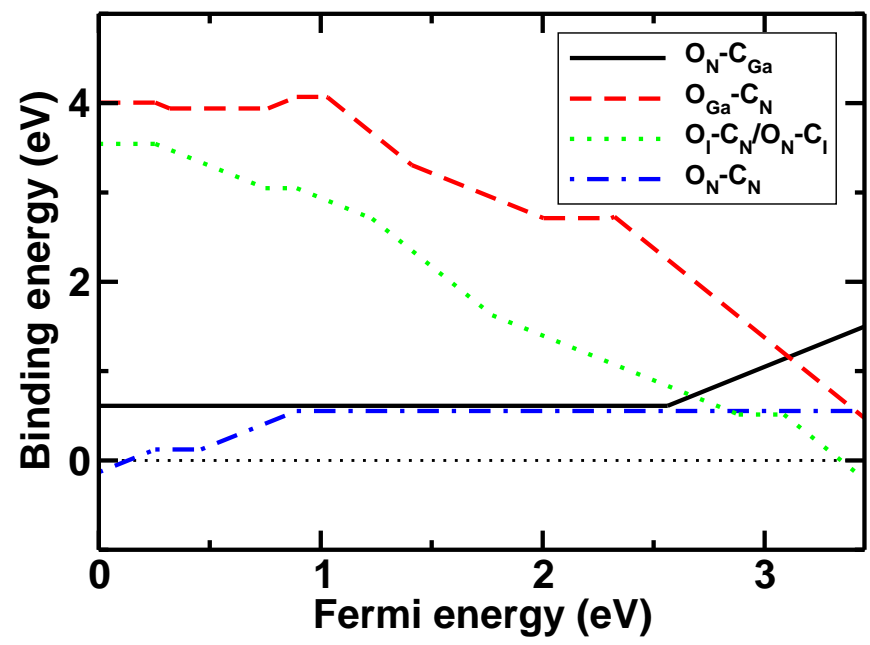

FIG. 20. Binding energies as a function of Fermi energy for $\mathrm{O}_{\mathrm{N}}-\mathrm{C}_{\mathrm{Ga}}$ (black solid line), $\mathrm{O}_{\mathrm{Ga}}-\mathrm{C}_{\mathrm{N}}$ (red dashed line), $\mathrm{O}_{\mathrm{I}}-\mathrm{C}_{\mathrm{N}} / \mathrm{O}_{\mathrm{N}}-\mathrm{C}_{\mathrm{I}}$ (green dotted line) and $\mathrm{O}_{\mathrm{N}}-\mathrm{C}_{\mathrm{N}}$ (blue dashed-dotted line).

the other complexes whose constituents are first nearest neighbors. The $\mathrm{O}_{\mathrm{Ga}}-\mathrm{C}_{\mathrm{N}}$ complex shows high binding energy with $4 \mathrm{eV}$ near the VBM. Then it starts to decrease when the Fermi energy approaches the CBM, reaching a value of $0.48 \mathrm{eV}$, which suggests week binding. In the case of $\mathrm{O}_{\mathrm{I}}-\mathrm{C}_{\mathrm{N}} / \mathrm{O}_{\mathrm{N}}-\mathrm{C}_{\mathrm{I}}$ complex, the binding energies are calculated with $\mathrm{O}_{I}$ and $\mathrm{C}_{N}$ as constituents as both $\mathrm{O}_{\mathrm{I}}-\mathrm{C}_{\mathrm{N}}$ and $\mathrm{O}_{\mathrm{N}}-\mathrm{C}_{\mathrm{I}}$ relax into the same structure with the pair of $\mathrm{O}_{\mathrm{I}}$ and $\mathrm{C}_{\mathrm{N}}$ rather than $\mathrm{O}_{\mathrm{N}}$ and $\mathrm{C}_{\mathrm{I}}$ (see Fig. 18). The binding energy is as high as $3.5 \mathrm{eV}$ when the Fermi energy is located near the VBM. Then it gradually decreases and reaches zero at $E_{F}=3.34 \mathrm{eV}$. Therefore this complex is unstable when the Fermi energy is located at $3.34 \mathrm{eV}$ or above.

\section{DISCUSSION}

\section{A. Comparison with Experimental Results}

In this section we compare our calculated results of the carbon related trap levels with the experimental counterparts found in literature. Experimentally obtained carbon related trap level energies are summarized in Table I. $E_{\mathrm{TH}}$ and $E_{\mathrm{OPT}}$ denote thermal and optical activation energies, respectively. The former is obtained by thermal techniques such as DLTS, whereas the latter is obtained by optical techniques such as DLOS. In our previous paper $^{5}$, we assigned the origins of these experimentally observed trap levels to the calculated results obtained by our HSE calculations for carbon-carbon/carbon-vacancy complexes. These assignments are also presented in the right column of Table I.

Our calculated results of the trap level positions for $\mathrm{C}-\mathrm{H}, \mathrm{C}-\mathrm{Si}$ and $\mathrm{C}-\mathrm{O}$ complexes are summarized in Ta- 
TABLE I. Experimentally obtained carbon related trap levels. Activation energies obtained by thermal technique such as DLTS and by optical technique such as DLOS are denoted by $E_{\mathrm{TH}}$ and $E_{\mathrm{OPT}}$, respectively (in $\mathrm{eV}$ ). Our assignments of the origins of these trap levels based on HSE calculations for carbon-carbon/carbon-vacancy complexes are also given.

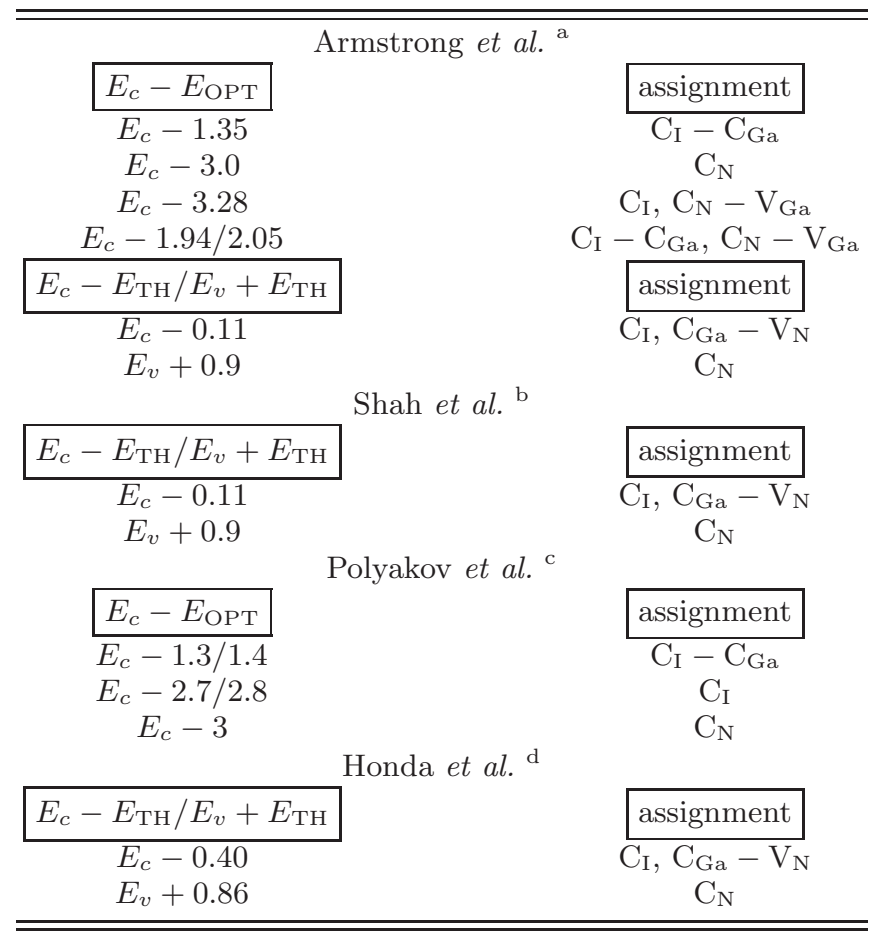

a Ref. 1 .

b Ref. 2 .

${ }^{c}$ Ref. 3.

d Ref. 4.

bles II, III and IV, respectively. The thermodynamic transition levels $\epsilon\left(q / q^{\prime}\right)$ correspond to the energy values for which the favorable charge states are changed from $q$ to $q^{\prime}$. They are obtained using the formation energies calculated in the previous section employing Eq. (9). Using $\epsilon\left(q / q^{\prime}\right)$, the thermal activation energy $\left(E_{\mathrm{TH}}\right)$ is expressed as $E_{\mathrm{TH}}=E_{g}-\epsilon\left(q / q^{\prime}\right)^{5}$. Since our formation energy calculations are based on the thermodynamic equilibrium, the calculated values of $\epsilon\left(q / q^{\prime}\right)$ and $E_{\mathrm{TH}}$ can be directly compared with the experimental values obtained by thermal techniques.

On the other hand, in order to compare the calculated results with the experimental trap level energies obtained by optical techniques, we need to compute the optical activation energy $\left(E_{\mathrm{OPT}}\right)$. This is obtained from $E_{\mathrm{TH}}$ with $E_{\mathrm{OPT}}=E_{\mathrm{TH}}+d_{\mathrm{FC}}$, where $d_{\mathrm{FC}}$ is the lattice relaxation energy (so-called Franck-Condon shift). In order to show the relation between $E_{\mathrm{TH}}$ and $E_{\mathrm{OPT}}$ with the FranckCondon shift $\left(d_{\mathrm{FC} 2}\right)$, schematic configuration coordinate diagram for $\mathrm{Si}_{\mathrm{Ga}}-\mathrm{C}_{\mathrm{N}}$ is given in Fig. 21 as a representative case. In this complex, the $(1+/ 0)$ transition level was obtained as $0.27 \mathrm{eV}$ (see Fig. 8). Thus the thermal activation energy is calculated as $3.18 \mathrm{eV}$. In order to

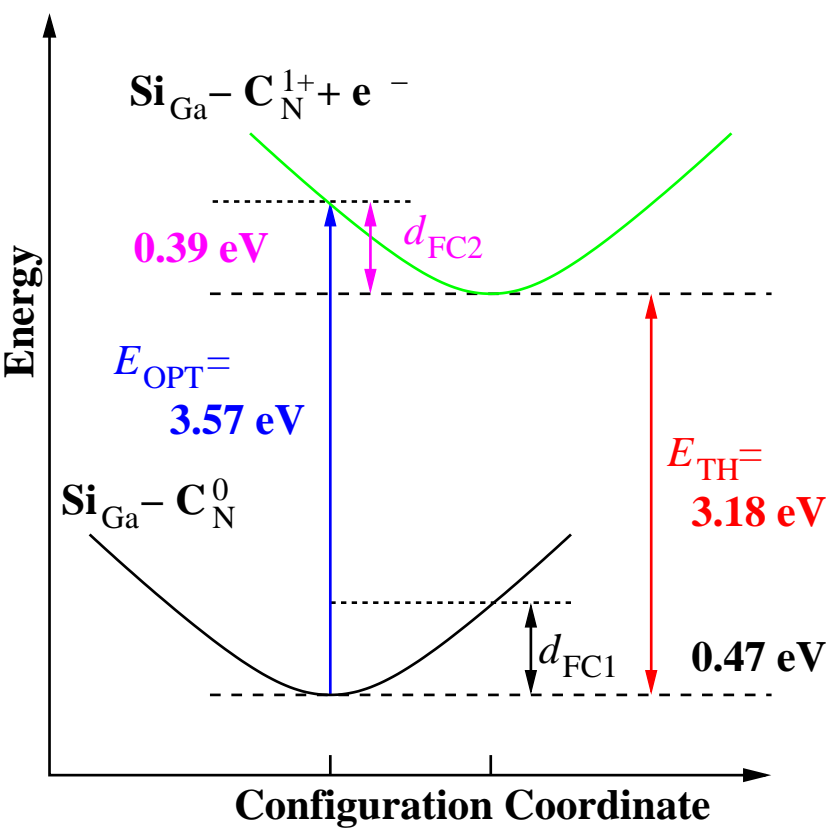

FIG. 21. Schematic configuration coordinate diagram describing optical and thermal processes by electron capture between the $1+$ and 0 charge states in $\mathrm{Si}_{\mathrm{Ga}}-\mathrm{C}_{\mathrm{N}}$ complex.

TABLE II. Thermodynamic transition levels $\left[\epsilon\left(q / q^{\prime}\right)\right]$, thermal activation energies $\left(E_{\mathrm{TH}}\right)$ and optical activation energies $\left(E_{\mathrm{OPT}}\right)$ for hydrogen-carbon complexes. The levels which do not appear within the band gap are denoted as horizontal bar. The energy levels close to the experimental ones are denoted in bold.

\begin{tabular}{ccccc}
\hline \hline Form & $\left(q / q^{\prime}\right)$ & $\epsilon\left(q / q^{\prime}\right)(\mathrm{eV})$ & $E_{\mathrm{TH}}(\mathrm{eV})$ & $E_{\mathrm{OPT}}(\mathrm{eV})$ \\
\hline $\mathrm{C}_{\mathrm{N}}-\mathrm{H}_{\mathrm{I}}$ & $(+/ 0)$ & 0.09 & $\mathbf{3 . 3 6}$ & - \\
$\mathrm{C}_{\mathrm{Ga}}-\mathrm{H}_{\mathrm{I}}$ & $(2+/ 0)$ & 2.27 & 1.18 & - \\
& $(2+/+)$ & 2.31 & 1.14 & $\mathbf{2 . 1 3}$ \\
& $(+/ 0)$ & 2.23 & 1.22 & $\mathbf{2 . 5 6}$ \\
\hline \hline
\end{tabular}

obtain the optical activation energy, the corresponding Franck-Condon shift $\left(d_{\mathrm{FC} 2}\right)$ is computed and obtained as $0.39 \mathrm{eV}$. This gives $3.57 \mathrm{eV}$ optical activation energy for the transition between $1+$ and 0 charge states.

Our calculated transition level positions and activation energies for $\mathrm{C}-\mathrm{H}$ complexes are reported in Table II. The $\mathrm{C}_{\mathrm{N}}-\mathrm{H}_{\mathrm{I}}$ complex has only one transition level, which is $(+/ 0)$ and its thermal activation energy is $3.36 \mathrm{eV}$. This energy is close to the experimental value of $3.20 \mathrm{eV}$ observed by Shah et $a .^{2}{ }^{2}$. The $\mathrm{C}_{\mathrm{Ga}}-\mathrm{H}_{\mathrm{I}}$ complex also has one transition level, $(2+/ 0)$, at $2.27 \mathrm{eV}$, whose thermal activation energy corresponds to $1.18 \mathrm{eV}$. In addition, two optical transitions are possible: $(2+/+)$ at $2.13 \mathrm{eV}$ and $(+/ 0)$ at $2.56 \mathrm{eV}$. The former may correspond to the trap at $E_{c}-1.94 / 2.05 \mathrm{eV}$ obtained by Armstrong et $a l .{ }^{1}$, whereas the latter may correspond to the trap at $E_{c}-2.7 / 2.8 \mathrm{eV}$ obtained by Polyakov et al. ${ }^{3}$.

The calculated transition levels obtained for $\mathrm{Si}-\mathrm{C}$ com- 
TABLE III. Thermodynamic transition levels $\left[\epsilon\left(q / q^{\prime}\right)\right]$, thermal activation energies $\left(E_{\mathrm{TH}}\right)$ and optical activation energies $\left(E_{\mathrm{OPT}}\right)$ for silicon-carbon complexes. The levels which do not appear within the band gap are denoted as horizontal bar. The energy levels close to the experimental ones are denoted in bold.

\begin{tabular}{cccrcc}
\hline \hline Form & $\left(q / q^{\prime}\right)$ & $\epsilon\left(q / q^{\prime}\right)(\mathrm{eV})$ & \multicolumn{1}{c}{$E_{\mathrm{TH}}(\mathrm{eV})$} & $E_{\mathrm{OPT}}(\mathrm{eV})$ \\
\hline $\mathrm{Si}_{\mathrm{Ga}}-\mathrm{C}_{\mathrm{N}}$ & $(+/ 0)$ & 0.27 & $\mathbf{3 . 1 8}$ & - \\
$\mathrm{Si}_{\mathrm{N}}-\mathrm{C}_{\mathrm{Ga}}$ & $(2+/+)$ & 0.68 & 2.77 & 3.42 \\
& $(+/ 0)$ & 1.51 & 1.94 & 2.36 \\
$\mathrm{Si}_{\mathrm{I}}-\mathrm{C}_{\mathrm{N}}$ & $(3+/ 2+)$ & 1.60 & 1.85 & $\mathbf{2 . 6 5}$ \\
& $(2+/+)$ & 2.26 & 1.19 & 2.28 \\
$\mathrm{Si}_{\mathrm{Ga}}-\mathrm{C}_{\mathrm{I}}$ & $(3+/ 2+)$ & 1.03 & 2.42 & - \\
& $(2+/+)$ & 1.71 & 1.74 & 2.55 \\
& $(+/ 0)$ & 2.60 & 0.85 & $\mathbf{1 . 4 3}$ \\
\hline \hline
\end{tabular}

plexes are summarized in Table III. The $(+/ 0)$ transition level of $\mathrm{Si}_{\mathrm{Ga}}-\mathrm{C}_{\mathrm{N}}$ complex has $E_{\mathrm{TH}}=3.18 \mathrm{eV}$. This energy value is close to the $E_{c}-3.20 \mathrm{eV}$ obtained by Shah et $a l .{ }^{2}$ The $(2+/+)$ level from the $\mathrm{Si}_{\mathrm{N}}-\mathrm{C}_{\mathrm{Ga}}$ complex has $E_{\mathrm{TH}}=2.77 \mathrm{eV}$ and $E_{\mathrm{OPT}}=3.42 \mathrm{eV}$. The former corresponds to the level at $E_{c}-2.69 \mathrm{eV}$ obtained by Shah et al. with DLTS ${ }^{2}$, while the latter has close energy to the level at $E_{c}-3.28 \mathrm{eV}$ observed by Armstrong et al. with DLOS ${ }^{1}$. However, the lowest formation energy for $\mathrm{Si}_{\mathrm{N}}-\mathrm{C}_{\mathrm{Ga}}$ is $5.77 \mathrm{eV}$ (see Fig. 8), which is high compared to other Si-C complexes. Using Eq. (10) with typical MOCVD growth temperature of $1323 \mathrm{~K}$, the concentration of this complex is negligible $\left(\sim 10^{1} \mathrm{~cm}^{-3}\right.$ at most). Thus we do not assign the levels from this complex to any experimentally observed trap levels in Tables III and V. The $(3+/ 2+)$ level from the $\mathrm{Si}_{\mathrm{I}}-\mathrm{C}_{\mathrm{N}}$ complex has $2.65 \mathrm{eV}$ optical activation energy. This value is very close to the trap level at $E_{c}-2.7 / 2.8 \mathrm{eV}$ observed by Polyakov et al. ${ }^{3}$. The $\mathrm{Si}_{\mathrm{Ga}}-\mathrm{C}_{\mathrm{I}}$ complex has negative binding energy up to $2.14 \mathrm{eV}$. Therefore only the $(+/ 0)$ level is likely to exist as one from stable form complexes. Its optical activation energy of $1.43 \mathrm{eV}$ is very close energy to the levels observed by Armstrong et al. at $E_{c}-1.35 \mathrm{eV}^{1}$ and by Polyakov et al. at $E_{c}-1.3 / 1.4 \mathrm{eV}^{3}$.

Finally we perform a comparison between our calculated transition levels for oxygen-carbon complexes and the experimentally observed ones. The $\mathrm{O}_{\mathrm{N}}-\mathrm{C}_{\mathrm{Ga}}$ complex is unlikely to form because both constituents are shallow donors and are expected to repel each other under any conditions. Therefore there is no experimentally observed trap levels which would correspond to the $(2+/+)$ trap level of the $\mathrm{O}_{\mathrm{N}}-\mathrm{C}_{\mathrm{Ga}}$ complex. The optical activation energy of $(+/ 0)$ of the $\mathrm{O}_{\mathrm{N}}-\mathrm{C}_{\mathrm{N}}$ complex is calculated to be $3.40 \mathrm{eV}$. This energy is close to the experimentally observed $E_{c}-3.28 \mathrm{eV}$ trap level ${ }^{1}$. The $(2+/+)$ level of the $\mathrm{O}_{\mathrm{Ga}}-\mathrm{C}_{\mathrm{N}}$ complex is located at $0.76 \mathrm{eV}$ with $2.69 \mathrm{eV}$ thermal activation energy. The former corresponds to the trap levels at $E_{v}+0.9 \mathrm{eV}$ observed by Armstrong et $a l^{1}$ and at $E_{v}+0.86 \mathrm{eV}$ observed by Honda et $a l^{4}$, whereas the latter corresponds to the trap
TABLE IV. Thermodynamic transition levels $\left[\epsilon\left(q / q^{\prime}\right)\right]$, thermal activation energies $\left(E_{\mathrm{TH}}\right)$ and optical activation energies $\left(E_{\mathrm{OPT}}\right)$ for oxygen-carbon complexes. The levels which do not appear within the band gap are denoted as horizontal bar. The energy levels close to the experimental ones are denoted in bold.

\begin{tabular}{ccccc}
\hline \hline Form & $\left(q / q^{\prime}\right)$ & $\epsilon\left(q / q^{\prime}\right)(\mathrm{eV})$ & $E_{\mathrm{TH}}(\mathrm{eV})$ & $E_{\mathrm{OPT}}(\mathrm{eV})$ \\
\hline $\mathrm{O}_{\mathrm{N}}-\mathrm{C}_{\mathrm{Ga}}$ & $(2+/+)$ & 2.56 & 0.89 & 1.77 \\
$\mathrm{O}_{\mathrm{N}}-\mathrm{C}_{\mathrm{N}}$ & $(+/ 0)$ & 0.46 & 2.99 & $\mathbf{3 . 4 0}$ \\
$\mathrm{O}_{\mathrm{Ga}}-\mathrm{C}_{\mathrm{N}}$ & $(3+/ 2+)$ & 0.32 & 3.13 & - \\
& $(2+/+)$ & 0.76 & 2.69 & - \\
& $(+/ 0)$ & 1.41 & 2.04 & 2.30 \\
& $(0 /-)$ & 2.00 & 1.45 & 1.88 \\
$\mathrm{O}_{\mathrm{I}}-\mathrm{C}_{\mathrm{N}} /$ & $(2+/ 2-)$ & 2.31 & 1.14 & 1.39 \\
$\mathrm{O}_{\mathrm{N}}-\mathrm{C}_{\mathrm{I}}$ & $(+/ 0)$ & $\mathbf{0 . 7 5}$ & $\mathbf{2 . 7 0}$ & - \\
& $(0 /-)$ & 2.77 & 1.68 & 2.35 \\
& & 2.88 & $\mathbf{0 . 5 7}$ & $\mathbf{1 . 5 3}$ \\
\hline \hline
\end{tabular}

level at $E_{c}-2.69 \mathrm{eV}$ measured by Shah et al. ${ }^{2}$. In addition, the optical activation energy of the $(0 /-)$ level $(1.88 \mathrm{eV})$ is close to the $E_{c}-1.94 / 2.05 \mathrm{eV}$ level reported by Armstrong et al. ${ }^{1}$ and that of $(-/ 2-)$ level $(1.39 \mathrm{eV})$ may correspond to the $E_{c}-1.35 \mathrm{eV}$ level measured by Armstrong et al. ${ }^{1}$ and the $E_{c}-1.3 / 1.4 \mathrm{eV}$ level obtained by Polyakov et al. ${ }^{3}$. However, as in the case of $\mathrm{Si}_{\mathrm{N}}-\mathrm{C}_{\mathrm{Ga}}$, $\mathrm{O}_{\mathrm{Ga}}-\mathrm{C}_{\mathrm{N}}$ has high formation energy with the value at least $6.96 \mathrm{eV}$ (see Fig. 16). Again, using Eq. (10) with the temperature of $1323 \mathrm{~K}$, the concentration of this complex is negligible $\left(<1 \mathrm{~cm}^{-3}\right)$. Thus we do not assign the levels from this complex to any experimentally observed trap levels in Tables IV and V.

The $(2+/+)$ level of $\mathrm{O}_{\mathrm{I}}-\mathrm{C}_{\mathrm{N}} / \mathrm{O}_{\mathrm{N}}-\mathrm{C}_{\mathrm{I}}$ complex has the $(2+/+)$ trap level at $0.75 \mathrm{eV}$ with $2.70 \mathrm{eV}$ thermal activation energy, which are very similar to the $(2+/+)$ level of $\mathrm{O}_{\mathrm{Ga}}-\mathrm{C}_{\mathrm{N}}$ complex. The $(0 /-)$ level of $\mathrm{O}_{\mathrm{I}}-\mathrm{C}_{\mathrm{N}} / \mathrm{O}_{\mathrm{N}}-\mathrm{C}_{\mathrm{I}}$ complex has $0.57 \mathrm{eV}$ thermal activation energy and $1.53 \mathrm{eV}$ optical activation energy. The former is close to the the trap level at $E_{c}-0.40 \mathrm{eV}$ observed by Honda et $a l^{4}$, while the latter is close to the trap level at $E_{c}-1.35 \mathrm{eV}$ observed by Armstrong et al. ${ }^{1}$ and at $E_{c}-1.3 / 1.4 \mathrm{eV}$ by Polyakov et $a .^{3}$.

Table V summarizes our assignments of the calculated values to the experimentally observed trap levels. The right most column corresponds to the $\mathrm{C}$ complexes with $\mathrm{H}$, Si or O. All these unintentional impurities contribute, with different efficacy, to the introduction of C-related trap levels in the band gap.

Furthermore, to provide additional information for the experimental groups, we also calculated vibrational frequencies of the complexes with interstitials ${ }^{40}$, which can be assigned to experimentally observed trap levels in order to provide information for the detection of these complexes. The frequencies for the stretching modes are summarized in Table VI. 
TABLE V. Assignments of the experimentally observed trap levels to our theoretically obtained trap levels considering all the defects considered. Assignments based on previous LDA/HSE calculations are also given. For experimental values, (T) denotes the level obtained by thermal techniques, whereas $(\mathrm{O})$ denotes the level obtained by optical techniques.

\begin{tabular}{|c|c|c|c|}
\hline experiment & $\begin{array}{c}\text { previous } \\
\text { LDA }^{\mathrm{e}} / \mathrm{HSE}^{\mathrm{f}}\end{array}$ & $\begin{array}{c}\text { our } \mathrm{HSE}^{\mathrm{g}} \\
\mathrm{C}, \mathrm{C}-\mathrm{C}, \mathrm{C}-\mathrm{V}\end{array}$ & $\begin{array}{c}\text { our HSE }{ }^{\mathrm{h}} \\
\mathrm{C}-\mathrm{H}, \mathrm{C}-\mathrm{Si}, \mathrm{C}-\mathrm{O}\end{array}$ \\
\hline$E_{v}+0.9^{\mathrm{a}}, E_{v}+0.86^{\mathrm{b}}(\mathrm{T})$ & $\mathrm{C}_{\mathrm{N}}$ & $\mathrm{C}_{\mathrm{N}}$ & $\frac{-}{\mathrm{O}_{\mathrm{I}}-\mathrm{C}_{\mathrm{N}} / \mathrm{O}_{\mathrm{N}}-\mathrm{C}_{\mathrm{I}}}$ \\
\hline$E_{c}-0.11^{\mathrm{a}}, E_{c}-0.13^{\mathrm{c}}(\mathrm{T})$ & $\mathrm{C}_{\mathrm{Ga}}$ & $\mathrm{C}_{\mathrm{I}}, \mathrm{C}_{\mathrm{Ga}}-\mathrm{V}_{\mathrm{N}}$ & - \\
\hline$E_{c}-0.40^{\mathrm{b}}(\mathrm{T})$ & - & $\mathrm{C}_{\mathrm{I}}, \mathrm{C}_{\mathrm{Ga}}-\mathrm{V}_{\mathrm{N}}$ & $\mathrm{O}_{\mathrm{I}}-\mathrm{C}_{\mathrm{N}} / \mathrm{O}_{\mathrm{N}}-\mathrm{C}_{\mathrm{I}}$ \\
\hline$E_{c}-1.35^{\mathrm{a}}, E_{c}-1.3 / 1.4^{\mathrm{d}}(\mathrm{O})$ & $\mathrm{C}_{\mathrm{I}}$ & $\mathrm{C}_{\mathrm{I}}-\mathrm{C}_{\mathrm{Ga}}$ & $\begin{array}{c}\mathrm{Si}_{\mathrm{Ga}}-\mathrm{C}_{\mathrm{I}} \\
\mathrm{O}_{\mathrm{I}}-\mathrm{C}_{\mathrm{N}} / \mathrm{O}_{\mathrm{N}}-\mathrm{C}_{\mathrm{I}}\end{array}$ \\
\hline$E_{c}-1.94 / 2.05^{\mathrm{a}}(\mathrm{O})$ & - & $\mathrm{C}_{\mathrm{I}}-\mathrm{C}_{\mathrm{Ga}}, \mathrm{C}_{\mathrm{N}}-\mathrm{V}_{\mathrm{Ga}}$ & $\mathrm{C}_{\mathrm{Ga}}-\mathrm{H}_{\mathrm{I}}$ \\
\hline$E_{c}-2.69^{\mathrm{c}}(\mathrm{T})$ & $\mathrm{C}_{\mathrm{N}} / \mathrm{V}_{\mathrm{Ga}}$ & $\mathrm{C}_{\mathrm{N}}$ & $\mathrm{O}_{\mathrm{I}}-\mathrm{C}_{\mathrm{N}} / \mathrm{O}_{\mathrm{N}}-\mathrm{C}_{\mathrm{I}}$ \\
\hline$E_{c}-2.7 / 2.8^{\mathrm{d}}(\mathrm{O})$ & - & $\mathrm{C}_{\mathrm{I}}$ & $\mathrm{C}_{\mathrm{Ga}}-\mathrm{H}_{\mathrm{I}}, \mathrm{Si}_{\mathrm{I}}-\mathrm{C}_{\mathrm{N}}$ \\
\hline$E_{c}-3.0^{\mathrm{a}}, E_{c}-3^{\mathrm{d}}(\mathrm{O})$ & $\mathrm{C}_{\mathrm{N}}$ & $\mathrm{C}_{\mathrm{N}}$ & - \\
\hline$E_{c}-3.20^{\mathrm{c}}(\mathrm{T})$ & $\mathrm{C}_{\mathrm{N}}$ & $\mathrm{C}_{\mathrm{N}}$ & $\mathrm{C}_{\mathrm{N}}-\mathrm{H}_{\mathrm{I}}, \mathrm{Si}_{\mathrm{Ga}}-\mathrm{C}_{\mathrm{N}}$ \\
\hline$E_{c}-3.28^{\mathrm{a}}(\mathrm{O})$ & $\mathrm{C}_{\mathrm{N}}$ & $\mathrm{C}_{\mathrm{I}}, \mathrm{C}_{\mathrm{N}}-\mathrm{V}_{\mathrm{Ga}}$ & $\mathrm{O}_{\mathrm{N}}-\mathrm{C}_{\mathrm{N}}$ \\
\hline
\end{tabular}

a Ref. 1.

b Ref. 4 .

${ }^{c}$ Ref. 2.

d Ref. 3.

e Ref. 22.

${ }^{f}$ Ref. 23.

g Ref. 5.

h This work.

TABLE VI. Vibrational frequencies for $\mathrm{C}_{\mathrm{N}}-\mathrm{H}_{\mathrm{I}}, \mathrm{C}_{\mathrm{Ga}}-\mathrm{H}_{\mathrm{I}}$, $\mathrm{Si}_{\mathrm{I}}-\mathrm{C}_{\mathrm{N}}, \mathrm{Si}_{\mathrm{Ga}}-\mathrm{C}_{\mathrm{I}}$ and $\mathrm{I}_{\mathrm{I}}-\mathrm{C}_{\mathrm{N}} / \mathrm{O}_{\mathrm{N}}-\mathrm{C}_{\mathrm{i}}$. The stretching mode frequencies are given in $\mathrm{cm}^{-3}$.

\begin{tabular}{lll}
\hline \hline Form & $q$ & vibrational frequency \\
\hline $\mathrm{C}_{\mathrm{N}}-\mathrm{H}_{\mathrm{I}}$ & $1+$ & 3023 \\
& 0 & 3062 \\
$\mathrm{C}_{\mathrm{Ga}}-\mathrm{H}_{\mathrm{I}}$ & $2+$ & 3656 \\
& $1+$ & 3041 \\
& 0 & 3109 \\
$\mathrm{Si}_{\mathrm{I}}-\mathrm{C}_{\mathrm{N}}$ & $3+$ & 1011 \\
& $2+$ & 911 \\
$\mathrm{Si}_{\mathrm{Ga}}-\mathrm{C}_{\mathrm{I}}$ & $1+$ & 1570 \\
& 0 & 1363 \\
$\mathrm{O}_{\mathrm{I}}-\mathrm{C}_{\mathrm{N}} /$ & $2+$ & 1779 \\
$\mathrm{O}_{\mathrm{N}}-\mathrm{C}_{\mathrm{I}}$ & $1+$ & 1449 \\
& 0 & 1258 \\
& $1-$ & 1176 \\
\hline \hline
\end{tabular}

\section{B. Defect Concentration}

In order to experimentally detect these C-related defects, they must have a concentration that is above the experimental measurable threshold. Therefore, in this subsection we calculate the concentrations of these defects to estimate the amount of carbon effectively incorporated in GaN.

The concentration of defect $i,\left[C_{i}\right]$, is determined by Eq. (10) using defect formation energy computed by Eq. (1) and growth temperature $T$. The formation en- ergy is a function of the Fermi level $\left(E_{\mathrm{F}}\right)$, therefore it is a variable here and must be determined self-consistently to satisfy the following charge neutrality condition:

$$
\sum_{i} q_{i}\left[C_{i}\right]-[n]+[p]=0
$$

where $q_{i}$ is the charge state, $[n]$ and $[p]$ are the electron and hole concentrations, respectively, and they are written as

$$
[n]=N_{c} \exp \left(-\frac{E_{g}-E_{\mathrm{F}}}{k_{\mathrm{B}} T}\right)
$$

where

$$
N_{c}=\frac{2\left(2 \pi m_{n}^{*} k_{\mathrm{B}} T\right)^{3 / 2}}{h^{3}}
$$

and

$$
[p]=N_{v} \exp \left(-\frac{E_{\mathrm{F}}}{k_{\mathrm{B}} T}\right)
$$

where

$$
N_{v}=\frac{2\left(2 \pi m_{p}^{*} k_{\mathrm{B}} T\right)^{3 / 2}}{h^{3}} .
$$

Here, $E_{g}$ is the band gap, $m_{n}^{*}\left(m_{p}^{*}\right)$ is the electron (hole) effective mass and $h$ is the Planck's constant. We used the effective masses equal to $0.2 m_{e}{ }^{41}$ for electron and $0.8 m_{e}{ }^{42}$ for hole with free electron mass $m_{e}$.

In the following the band gap value $\left(E_{g}=3.45 \mathrm{eV}\right)$ and the growth temperature $(T=1323 \mathrm{~K}$ as typical MOCVD 
growth temperature) are fixed to obtain equilibrium Fermi energy in solving Eq. (11). In order to consider different carbon concentration scenarios, we introduce a scaling factor $\alpha$ for the carbon concentration following the method by Wright ${ }^{39}$. We consider three different situations, i.e. low carbon ( $\left.\mathrm{LC}, 1 \times 10^{15} \mathrm{~cm}^{-3}\right)$, mid carbon $\left(\mathrm{MC}, 1 \times 10^{17} \mathrm{~cm}^{-3}\right)$ and high carbon $\left(\mathrm{HC}, 1 \times 10^{19} \mathrm{~cm}^{-3}\right.$ ) concentrations. In the LC situation, the total $\mathrm{C}$ concentration is expressed by

$$
1 \times 10^{15} \mathrm{~cm}^{-3}=\alpha \sum_{j}\left[C_{j}\right]=\alpha\left[C_{\mathrm{CN}^{1-}}\right]+\alpha\left[C_{\mathrm{C}_{\mathrm{N}}}\right]+\cdots,
$$

where $\left[C_{j}\right]$ denotes the concentrations for all kinds of carbon related defects with different charge states. Under the constraint described by Eq. (16), $\alpha$ and $E_{F}$ are determined by solving Eq. (11) iteratively. We considered two different situations. In the first case (a), one assumes that $\mathrm{C}$, vacancy $(\mathrm{V})$ and their complexes are the only electrically active defects in the system. In the second case (b), all defects considered $(\mathrm{H}, \mathrm{Si}, \mathrm{O}$ and their complexes with $\mathrm{C}$ as well as $\mathrm{C}$ and $\mathrm{V}$ ) are electrically active in the system. The results are summarized in Tables VII and VIII, where only defects with more than $1 \times 10^{10} \mathrm{~cm}^{-3}$ concentration are shown. The formation energies for these defects with substantial concentrations are plotted in Figs. 22 and 23 in the respective cases.

In the case (a), $E_{F}^{\mathrm{eq}}$ is pinned at near the mid gap $(1.92 \mathrm{eV})$ regardless of the $\mathrm{C}$ concentrations and growth conditions. Among the donors, $\mathrm{V}_{\mathrm{N}}^{1+}$ is the dominant one. In addition, as the $\mathrm{C}$ concentration is increased, $\mathrm{C}_{\mathrm{Ga}}^{1+}$ and $\mathrm{C}_{\mathrm{I}}^{1+}$ start to have substantial presence with significant concentrations. $\mathrm{C}_{\mathrm{N}}^{1-}$ is the only acceptor-like defect with a substantial amount present. In addition to these donor and acceptor defects, $\mathrm{C}_{\mathrm{N}}^{0}, \mathrm{~V}_{\mathrm{N}}^{0}$ and $\mathrm{C}_{\mathrm{N}}-\mathrm{C}_{\mathrm{Ga}}^{0}$ also exist as neutral defects. The position of $E_{F}^{\mathrm{eq}}$ corresponds to the intersection of the formation energies of the $\mathrm{C}_{\mathrm{N}}^{1-}$ and $\mathrm{V}_{\mathrm{N}}^{1+}$ as shown in Fig. 22. The low carrier concentrations resulting in his case leads to a semi-insulating behavior of the system.

Next we consider the case (b). Among the donor defects, $\mathrm{Si}_{\mathrm{Ga}}{ }^{1+}$ is the dominant impurity. This can be expected from its low formation energy. Furthermore, this is the dominant form of defect considered here regardless of the total concentration of $\mathrm{C}$ and of the growth environment. Besides $\mathrm{Si}_{\mathrm{Ga}}{ }^{1+}$, substantial amounts of $\mathrm{H}_{\mathrm{I}}^{1+}$ and $\mathrm{O}_{\mathrm{N}}^{1+}$ exist as donors. There are little C-related donor defects unlike the case (a). Among the acceptor defects, $\mathrm{C}_{\mathrm{N}}^{1-}$ has the majority presence. There are sizable amounts of $\mathrm{H}_{\mathrm{I}}^{1-}$ in particular in N-rich conditions, and $\mathrm{V}_{\mathrm{Ga}}^{2-}$ and $\mathrm{V}_{\mathrm{Ga}}^{3-}$ increases when the $E_{F}^{\mathrm{eq}}$ approaches the $\mathrm{CBM}$ in N-rich conditions. Except for $\mathrm{C}_{\mathrm{N}}^{0}$ with $\mathrm{HC}$ in Garich conditions, neutral defects consist of C-related complexes. Among them, $\mathrm{Si}_{\mathrm{Ga}}-\mathrm{C}_{\mathrm{N}}^{0}$ is the dominant form.

Focusing on the C-related defects, regardless of the total carbon concentrations, $\mathrm{Si}_{\mathrm{Ga}}-\mathrm{C}_{\mathrm{N}}^{0}$ is the dominant form in Ga-rich conditions, whereas $\mathrm{C}_{\mathrm{N}}^{1-}$ is the domi-
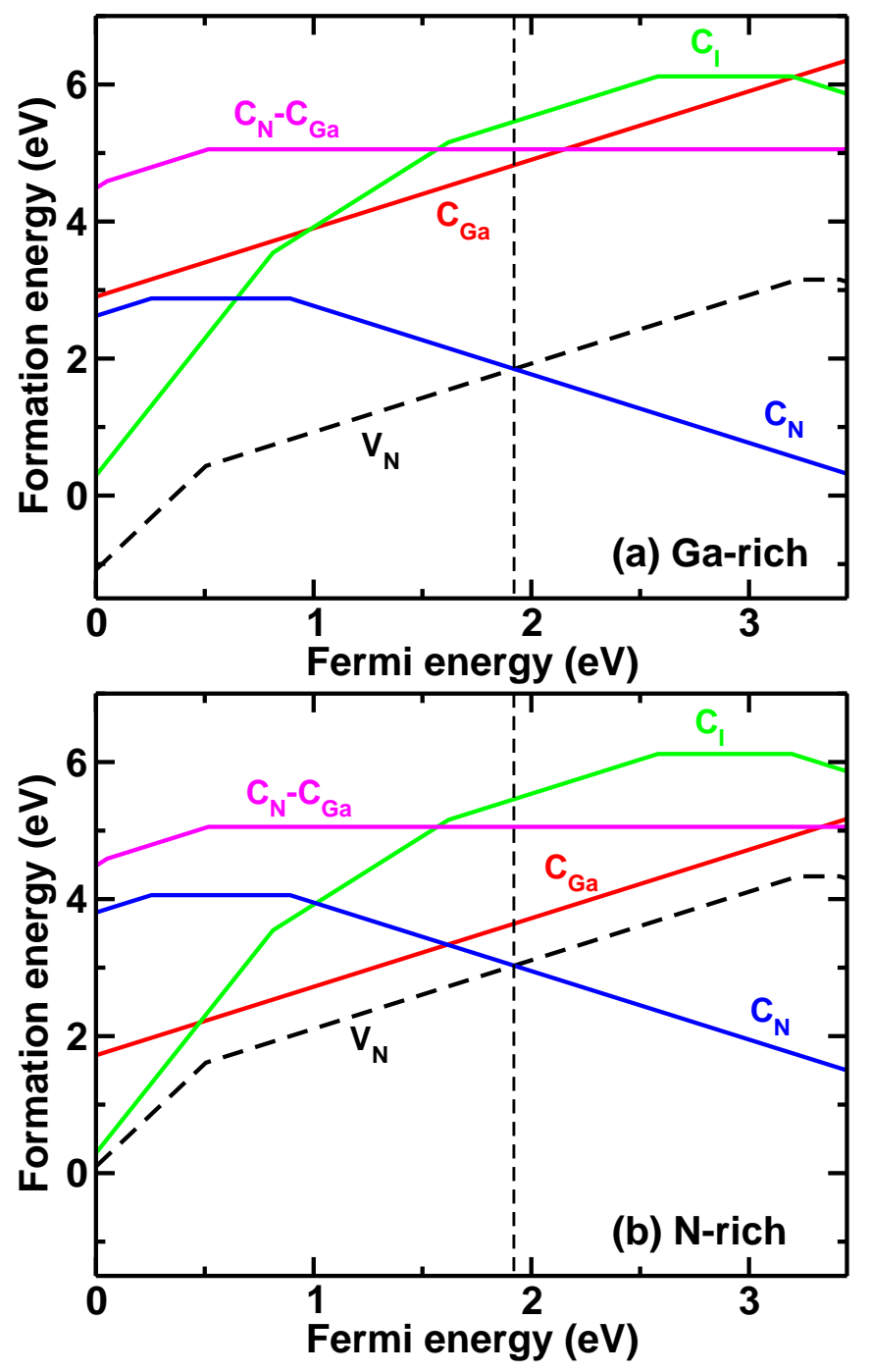

FIG. 22. Formation energies as a function of Fermi energy for defects with concentrations more than $1 \times 10^{10} \mathrm{~cm}^{-3}$ in (a) Ga-rich and (b) N-rich conditions. The C-related formation energies are plotted with solid lines, while non C-related ones are with dashed lines. The dashed vertical bar corresponds to the equilibrium Fermi energy obtained by the charge neutrality conditions.

nant form in N-rich conditions. This means that when the total $\mathrm{C}$ concentration increases, those of $\mathrm{Si}_{\mathrm{Ga}}-\mathrm{C}_{\mathrm{N}}^{0}$ and $\mathrm{C}_{\mathrm{N}}^{1-}$ increase as well. While the concentration of $\mathrm{Si}_{\mathrm{Ga}}-\mathrm{C}_{\mathrm{N}}^{0}$ has no dependency on the value of $E_{F}$, the increase of $\mathrm{C}_{\mathrm{N}}^{1-}$ results from the lower value of its formation energy, leading to the higher value of the $E_{F}$. As a result, the value $E_{F}^{\mathrm{eq}}$ becomes higher, when the total $\mathrm{C}$ concentration is changed from low (LC) to high (HC). Additionally, when the same $\mathrm{C}$ concentration is present both in Ga-rich and N-rich conditions, $E_{F}$ is higher in N-rich conditions than in Ga-rich conditions in order to have the same formation energies in both situations. This is the reason why $E_{F}^{\mathrm{eq}}$ is higher in N-rich conditions than in Ga-rich conditions. Comparing the 
TABLE VII. Concentrations of $\mathrm{C}$ and vacancies in the system. Only the ones with more than $10^{10} \mathrm{~cm}^{-3}$ are shown. Three different $\mathrm{C}$ concentrations are denoted as LC (low $\mathrm{C}$ concentration), MC (medium $\mathrm{C}$ concentration) and $\mathrm{HC}$ (high $\mathrm{C}$ concentration). $E_{F}^{\mathrm{eq}}$ denotes the equilibrium Fermi energy in eV. Highest $\mathrm{C}$ concentrations in each condition are denoted in bold. All the concentrations are in units of $\mathrm{cm}^{-3}$.

\begin{tabular}{|c|c|c|c|c|c|c|}
\hline & \multicolumn{2}{|c|}{$\mathrm{LC}\left(10^{15} \mathrm{~cm}^{-3}\right)$} & \multicolumn{2}{|c|}{$\mathrm{MC}\left(10^{17} \mathrm{~cm}^{-3}\right)$} & \multicolumn{2}{|c|}{$\mathrm{HC}\left(10^{19} \mathrm{~cm}^{-3}\right)$} \\
\hline & Ga-rich & N-rich & Ga-rich & N-rich & Ga-rich & N-rich \\
\hline$E_{F}^{\mathrm{eq}}$ & 1.920 & 1.920 & 1.921 & 1.921 & 1.921 & 1.922 \\
\hline$\alpha$ & $2.50 \times 10^{-1}$ & $7.85 \times 10^{3}$ & $2.48 \times 10^{1}$ & $7.78 \times 10^{5}$ & $2.48 \times 10^{3}$ & $7.72 \times 10^{7}$ \\
\hline$[n]$ & $3.09 \times 10^{13}$ & $3.09 \times 10^{13}$ & $3.11 \times 10^{13}$ & $3.11 \times 10^{13}$ & $3.11 \times 10^{13}$ & $3.14 \times 10^{13}$ \\
\hline$[p]$ & $8.07 \times 10^{12}$ & $8.07 \times 10^{12}$ & $8.00 \times 10^{12}$ & $8.00 \times 10^{12}$ & $8.00 \times 10^{12}$ & $7.93 \times 10^{12}$ \\
\hline$\left[\mathrm{C}_{\mathrm{Ga}}^{1+}\right]$ & $<10^{10}$ & $4.70 \times 10^{12}$ & $<10^{10}$ & $4.62 \times 10^{14}$ & $<10^{10}$ & $4.54 \times 10^{16}$ \\
\hline $\mathrm{C}_{\mathrm{I}}^{1+7}$ & $<10^{10}$ & $<10^{10}$ & $<10^{10}$ & $<10^{10}$ & $<10^{10}$ & $6.54 \times 10^{10}$ \\
\hline $\mathrm{V}_{\mathrm{N}}^{1+-}$ & $1.00 \times 10^{15}$ & $1.00 \times 10^{15}$ & $1.00 \times 10^{17}$ & $9.99 \times 10^{16}$ & $1.00 \times 10^{19}$ & $9.82 \times 10^{18}$ \\
\hline $\left.\mathrm{C}_{\mathrm{N}}^{1-}\right]$ & $1.00 \times 10^{15}$ & $9.95 \times 10^{14}$ & $1.00 \times 10^{17}$ & $9.95 \times 10^{16}$ & $1.00 \times 10^{19}$ & $9.95 \times 10^{18}$ \\
\hline$\left[\mathrm{C}_{\mathrm{N}}^{0}\right]$ & $1.21 \times 10^{11}$ & $1.20 \times 10^{11}$ & $1.20 \times 10^{13}$ & $1.19 \times 10^{13}$ & $1.20 \times 10^{15}$ & $1.18 \times 10^{15}$ \\
\hline$\left[\mathrm{C}_{\mathrm{N}}-\mathrm{C}_{\mathrm{Ga}}^{0}\right]$ & $<10^{10}$ & $<10^{10}$ & $<10^{10}$ & $<10^{10}$ & $<10^{10}$ & $7.59 \times 10^{11}$ \\
\hline$\left[\mathrm{V}_{\mathrm{N}}^{0}\right]$ & $<10^{10}$ & $1.09 \times 10^{10}$ & $1.08 \times 10^{11}$ & $1.08 \times 10^{12}$ & $1.08 \times 10^{14}$ & $1.07 \times 10^{14}$ \\
\hline
\end{tabular}

TABLE VIII. Concentrations of all defects ( $\mathrm{H}$, Si and $\mathrm{O}$ as well as $\mathrm{C}$ and vacancies) in the system. Only the ones with more than $10^{10} \mathrm{~cm}^{-3}$ are shown. Three different $\mathrm{C}$ concentrations are denoted as $\mathrm{LC}$ (low $\mathrm{C}$ concentration), MC (medium $\mathrm{C}$ concentration) and $\mathrm{HC}$ (high $\mathrm{C}$ concentration). $E_{F}^{\mathrm{eq}}$ denotes the equilibrium Fermi energy in eV. Highest $\mathrm{C}$ concentrations in each condition are denoted in bold. All the concentrations are in units of $\mathrm{cm}^{-3}$.

\begin{tabular}{|c|c|c|c|c|c|c|}
\hline & \multicolumn{2}{|c|}{$\mathrm{LC}\left(10^{15} \mathrm{~cm}^{-3}\right)$} & \multicolumn{2}{|c|}{$\mathrm{MC}\left(10^{17} \mathrm{~cm}^{-3}\right)$} & \multicolumn{2}{|c|}{$\mathrm{HC}\left(10^{19} \mathrm{~cm}^{-3}\right)$} \\
\hline & Ga-rich & N-rich & Ga-rich & N-rich & Ga-rich & N-rich \\
\hline$E_{F}^{\mathrm{eq}}$ & 2.548 & 3.012 & 2.806 & 3.189 & 2.962 & 3.333 \\
\hline$\alpha$ & $4.59 \times 10^{-6}$ & $4.88 \times 10^{-1}$ & $4.41 \times 10^{-4}$ & $1.13 \times 10^{1}$ & $3.93 \times 10^{-2}$ & $3.25 \times 10^{2}$ \\
\hline$[n]$ & $7.62 \times 10^{15}$ & $4.46 \times 10^{17}$ & $7.32 \times 10^{16}$ & $2.11 \times 10^{18}$ & $2.88 \times 10^{17}$ & $7.45 \times 10^{18}$ \\
\hline$[p]$ & $3.27 \times 10^{10}$ & $<10^{10}$ & $<10^{10}$ & $<10^{10}$ & $<10^{10}$ & $<10^{10}$ \\
\hline$\left\lceil\mathrm{H}_{\mathrm{I}}^{1+}\right\rceil$ & $2.68 \times 10^{10}$ & $4.87 \times 10^{13}$ & $2.68 \times 10^{11}$ & $2.38 \times 10^{14}$ & $6.09 \times 10^{12}$ & $1.94 \times 10^{15}$ \\
\hline$\left[\mathrm{Si}_{\mathrm{Ga}}^{1+}\right]$ & $6.18 \times 10^{15}$ & $3.55 \times 10^{17}$ & $6.19 \times 10^{16}$ & $1.74 \times 10^{18}$ & $1.40 \times 10^{18}$ & $1.42 \times 10^{19}$ \\
\hline$\left[\mathrm{O}_{\mathrm{N}}^{1+}\right]$ & $1.50 \times 10^{15}$ & $9.70 \times 10^{16}$ & $1.50 \times 10^{16}$ & $4.75 \times 10^{17}$ & $3.40 \times 10^{17}$ & $3.86 \times 10^{18}$ \\
\hline$\left[\mathrm{C}_{\mathrm{N}}^{1-}\right]$ & $4.52 \times 10^{12}$ & $8.93 \times 10^{14}$ & $4.19 \times 10^{15}$ & $9.75 \times 10^{16}$ & $1.46 \times 10^{18}$ & $9.93 \times 10^{18}$ \\
\hline$\left[\mathrm{H}_{\mathrm{I}}^{1-}\right]$ & $<10^{10}$ & $6.65 \times 10^{13}$ & $<10^{10}$ & $7.26 \times 10^{15}$ & $3.46 \times 10^{12}$ & $7.39 \times 10^{17}$ \\
\hline$\left[\mathrm{V}_{\mathrm{Ga}}^{2-}\right]$ & $<10^{10}$ & $<10^{10}$ & $<10^{10}$ & $<10^{10}$ & $<10^{10}$ & $4.68 \times 10^{10}$ \\
\hline$\left[\mathrm{V}_{\mathrm{Ga}}^{3-}\right]$ & $<10^{10}$ & $<10^{10}$ & $<10^{10}$ & $1.41 \times 10^{11}$ & $<10^{10}$ & $1.79 \times 10^{14}$ \\
\hline$\left[\mathrm{C}_{\mathrm{N}}^{0}\right]$ & $<10^{10}$ & $<10^{10}$ & $<10^{10}$ & $<10^{10}$ & $1.90 \times 10^{10}$ & $<10^{10}$ \\
\hline$\left[\mathrm{C}_{\mathrm{N}}-\mathrm{H}_{\mathrm{I}}^{0}\right]$ & $4.21 \times 10^{11}$ & $1.42 \times 10^{11}$ & $4.05 \times 10^{12}$ & $3.28 \times 10^{12}$ & $3.61 \times 10^{14}$ & $9.45 \times 10^{13}$ \\
\hline$\left[\mathrm{C}_{\mathrm{Ga}}-\mathrm{H}_{\mathrm{I}}^{0}\right]$ & $<10^{10}$ & $<10^{10}$ & $<10^{10}$ & $<10^{10}$ & $<10^{10}$ & $2.93 \times 10^{10}$ \\
\hline$\left[\mathrm{Si}_{\mathrm{Ga}}-\mathrm{C}_{\mathrm{N}}^{0}\right]$ & $9.78 \times 10^{14}$ & $1.04 \times 10^{14}$ & $9.42 \times 10^{16}$ & $2.41 \times 10^{15}$ & $8.39 \times 10^{18}$ & $6.95 \times 10^{16}$ \\
\hline$\left[\mathrm{O}_{\mathrm{N}}-\mathrm{C}_{\mathrm{N}}^{0}\right]$ & $1.72 \times 10^{13}$ & $2.06 \times 10^{12}$ & $1.65 \times 10^{15}$ & $4.77 \times 10^{13}$ & $1.47 \times 10^{17}$ & $1.37 \times 10^{15}$ \\
\hline
\end{tabular}

two different cases, unintentional impurities such as $\mathrm{H}$, $\mathrm{Si}$ and $\mathrm{O}$ are the mostly responsible for $n$-type behavior in GaN rather than native defects. If the amount of unintentional impurities, in particular Si and O, is kept low, then the situation is close to the case (a) and semiinsulating GaN is readily obtained. In light of all these results, it is important to consider again the experimental findings of Tompkins and coworkers. ${ }^{25}$ In Ref. 25, the authors posit the presence of an unknown forms of carbon in their GaN sample in addition to acceptor type $\mathrm{C}_{\mathrm{N}}^{1-}$. Our results indicate that the neutral $\mathrm{Si}_{\mathrm{Ga}}-\mathrm{C}_{\mathrm{N}}$ complex is a likely candidate for this unknown form of carbon in
GaN.

\section{CONCLUSION}

Various carbon based complexes in GaN were studied by using HSE hybrid density functionals within the framework of generalized Kohn-Sham density functional theory. Extending our previous work on carboncarbon/carbon-vacancy complexes, we have considered complexes of carbon with other types of unintentional impurities, i.e. hydrogen $(\mathrm{H}-\mathrm{C})$, silicon ( $\mathrm{Si}-\mathrm{C})$ and oxy- 

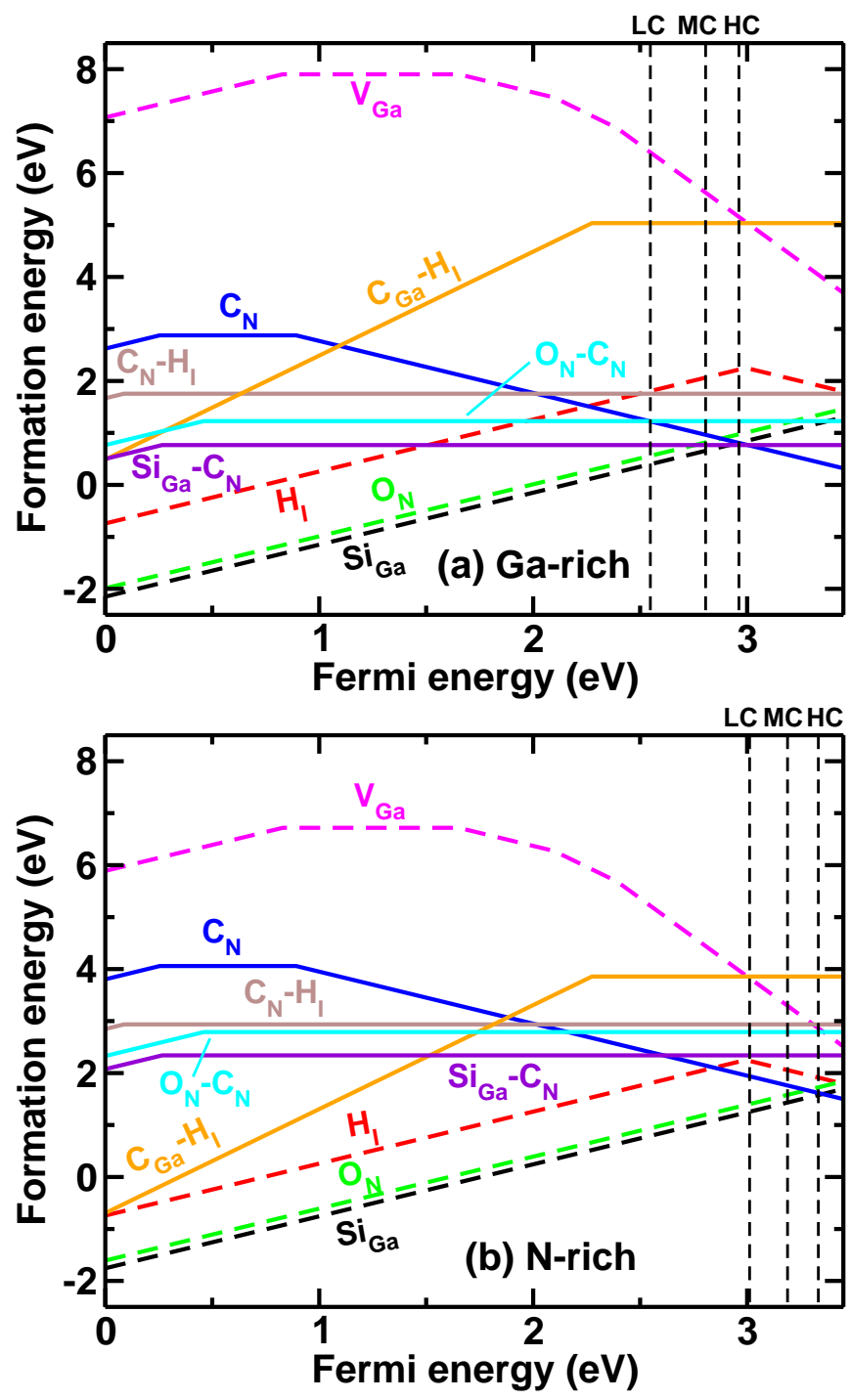

FIG. 23. Formation energies as a function of Fermi energy for defects with concentrations more than $1 \times 10^{10} \mathrm{~cm}^{-3}$ in (a) Ga-rich and (b) N-rich conditions. The C-related formation energies are plotted with solid lines, while non C-related ones are with dashed lines. The dashed vertical bars correspond to the equilibrium Fermi energy obtained by the charge neutrality conditions.

gen $(\mathrm{O}-\mathrm{C})$. The structures of these complexes were fully optimized. From the computed total energies, defect formation energies were obtained. Using the formation energies, binding energies of complexes and the transition levels were evaluated. Both thermal and optical activation energies were derived from the transition levels to compare our calculated results with the experimentally observed carbon related trap levels in GaN.

Two types of $\mathrm{H}-\mathrm{C}$ complexes were considered: $\mathrm{C}_{\mathrm{N}}-\mathrm{H}_{\mathrm{I}}$ and $\mathrm{C}_{\mathrm{Ga}}-\mathrm{H}_{\mathrm{I}}$. The $(+/ 0)$ transition level of $\mathrm{C}_{\mathrm{N}}-\mathrm{H}_{\mathrm{I}}$ at $0.09 \mathrm{eV}$ above the VBM has $E_{\mathrm{TH}}=3.36 \mathrm{eV}$ and this may correspond to $E_{c}-3.20$ level observed by Shah et $a .^{2}$. The optical transition levels $(2+/+)$ and
$(+/ 0)$ of $\mathrm{C}_{\mathrm{Ga}}-\mathrm{H}_{\mathrm{I}}$ has $E_{\mathrm{OPT}}=2.13$ and $2.56, \mathrm{eV}$, respectively. The former corresponds to the experimentally observed $E_{c}-1.94 / 2.05 \mathrm{eV}$ trap level ${ }^{1}$, whereas the latter corresponds to the $E_{c}-2.7 / 2.8 \mathrm{eV}$ trap level ${ }^{3}$.

Four different $\mathrm{Si}-\mathrm{C}$ complexes were examined: $\mathrm{Si}_{\mathrm{Ga}}-\mathrm{C}_{\mathrm{N}}, \mathrm{Si}_{\mathrm{N}}-\mathrm{C}_{\mathrm{Ga}}, \mathrm{Si}_{\mathrm{I}}-\mathrm{C}_{\mathrm{N}}$ and $\mathrm{Si}_{\mathrm{Ga}}-\mathrm{C}_{\mathrm{I}}$. Among them, $\mathrm{Si}_{\mathrm{Ga}}-\mathrm{C}_{\mathrm{N}}$ has the lowest formation energy. Its $(+/ 0)$ donor level at $0.27 \mathrm{eV}\left(E_{\mathrm{TH}}=3.18 \mathrm{eV}\right)$ corresponds to the experimentally observed $E_{c}-3.20 \mathrm{eV}$ trap level. The $(3+/ 2+)$ level of $\mathrm{Si}_{\mathrm{I}}-\mathrm{C}_{\mathrm{N}}$ has $2.65 \mathrm{eV}$ transition level, which can be assigned to $E_{c}-2.7 / 2.8 \mathrm{eV}$ level $^{3}$. Finally, the $(+/ 0)$ of $\mathrm{Si}_{\mathrm{Ga}}-\mathrm{C}_{\mathrm{I}}$ level has $E_{\mathrm{OPT}}=1.43 \mathrm{eV}$ optical activation energy and this value is very close to $E_{c}-1.35 \mathrm{eV}$ and $E_{c}-1.3 / 1.4 \mathrm{eV}$ levels observed by Armstrong et al. ${ }^{1}$ and by Polyakov et al. ${ }^{3}$. Note that $\mathrm{Si}_{\mathrm{N}}-\mathrm{C}_{\mathrm{Ga}}$ complex was excluded from the assignment because it has low concentration with high formation energy compared to other $\mathrm{Si}-\mathrm{C}$ complexes.

Five different $\mathrm{O}-\mathrm{C}$ complexes were studied. $\mathrm{O}_{\mathrm{I}}-\mathrm{C}_{\mathrm{N}}$ and $\mathrm{O}_{\mathrm{N}}-\mathrm{C}_{\mathrm{I}}$ has the same configuration after the full geometry optimization. Thus, four different complexes were considered in practice. The $(2+/+)$ level of $\mathrm{O}_{\mathrm{I}}-\mathrm{C}_{\mathrm{N}} / \mathrm{O}_{\mathrm{N}}-\mathrm{C}_{\mathrm{I}}$ is located at $0.75 \mathrm{eV}\left(E_{\mathrm{TH}}=2.70 \mathrm{eV}\right)$ above the VBM. Experimentally observed $E_{v}+0.9 \mathrm{eV}^{1}$ and $E_{v}+0.86 \mathrm{eV}^{4}$ levels as well as $E_{c}-2.69 \mathrm{eV}$ can be assigned to this level. The $(0 /-)$ level of $\mathrm{O}_{\mathrm{I}}-\mathrm{C}_{\mathrm{N}} / \mathrm{O}_{\mathrm{N}}-\mathrm{C}_{\mathrm{I}}$ has $E_{\mathrm{TH}}=0.57 \mathrm{eV}$ and $E_{\mathrm{OPT}}=1.53 \mathrm{eV}$. The former can be assigned to the thermally detected $E_{c}-0.40 \mathrm{eV}$ level $^{4}$ and the latter has close energy to the optically observed $E_{c}-1.35 \mathrm{eV}$ and $E_{c}-1.3 / 1.4 \mathrm{eV}$ levels. Finally the $(+/ 0)$ level of the $\mathrm{O}_{\mathrm{N}}-\mathrm{C}_{\mathrm{N}}$ complex, which is a second nearest neighbor pair, has $E_{\mathrm{OPT}}=3.40 \mathrm{eV}$, which can be assigned to the $E_{c}-3.28 \mathrm{eV}$ trap level. As in the case of $\mathrm{Si}_{\mathrm{N}}-\mathrm{C}_{\mathrm{Ga}}$, $\mathrm{O}_{\mathrm{Ga}}-\mathrm{C}_{\mathrm{N}}$ complex was excluded from the assignment because it has low concentration with high formation energy compared to other $\mathrm{O}-\mathrm{C}$ complexes.

From the analysis of the impurity concentration we have found that when only carbon and vacancies are considered as electrically active defects, Fermi energy is pinned near the mid gap with $1.92 \mathrm{eV}$ value regardless of the total carbon concentrations and growth conditions. This equilibrium Fermi energy corresponds to the intersection of the formation energies of $\mathrm{V}_{\mathrm{N}}^{1+}$ and $\mathrm{C}_{\mathrm{N}}^{1-}$. In this situation carrier concentration is low and semi-insulating behavior can be expected. Other than the $\mathrm{C}_{\mathrm{N}}$ and $\mathrm{V}_{\mathrm{N}}$, $\mathrm{C}_{\mathrm{Ga}}, \mathrm{C}_{\mathrm{I}}$ and $\mathrm{C}_{\mathrm{N}}-\mathrm{C}_{\mathrm{Ga}}$ show substantial presence with increasing total carbon concentrations.

When hydrogen, silicon and oxygen are also considered as electrically active defects besides carbon and vacancies, The situation is drastically changed. The equilibrium Fermi energy is closer to conduction band. It is $\sim 2.5 \mathrm{eV}$ with low carbon concentration situation in Garich conditions and it becomes $\sim 3.3 \mathrm{eV}$ with high carbon concentration situation in N-rich conditions. The carrier concentration is much higher, as high as $7.45 \times 10^{18} \mathrm{~cm}^{-3}$. Main donor defects are $\mathrm{H}, \mathrm{Si}$ and $\mathrm{O}$, in particular $\mathrm{Si}_{\mathrm{Ga}}$. No C-related donors have substantial concentrations.

As for acceptors, $\mathrm{C}_{\mathrm{N}}^{1-}$ is dominant. $\mathrm{H}_{\mathrm{I}}$ and $\mathrm{V}_{\mathrm{Ga}}$ also 
have substantial concentrations with increasing carbon concentrations. Neutral defects are mostly C-related complexes, among which $\mathrm{Si}_{\mathrm{Ga}}-\mathrm{C}_{\mathrm{N}}^{0}$ is the most dominant form. This neutral complex is a likely candidate for the unknown form of carbon in GaN observed in experimental results.

\section{ACKNOWLEDGMENTS}

The authors thank K. Jones and R. Tompkins of the Army Research Laboratory, T. Moustakas of Boston University and R. Kaplar of Sandia National Laboratory for many discussions and their help in understanding the experimental techniques. The authors are grateful to A. Wright, S. Lee and N. Modine from Sandia National Laboratory for discussing the result of our work. The authors gratefully acknowledge financial support from the U. S. Army Research Laboratory through the Collaborative Research Alliance (CRA) Grant No. W911NF-12-2-0023 for MultiScale multidisciplinary Modeling of Electronic Materials (MSME). This work was performed using DoD HPCMP supercomputing resources and computational resources provided by the 2014 Army Research Office Grant No. W911NF-14-1-0432 DURIP Award made to E. Bellotti.
1 A. Armstrong, A. R. Arehart, D. Green, U. K. Mishra, J. S. Speck, and S. A. Ringel, Journal of Applied Physics 98, 053704 (2005).

2 P. Shah, R. Dedhia, R. Tompkins, E. Viveiros, and K. Jones, Solid-State Electronics 78, 121 (2012).

3 A. Y. Polyakov, N. B. Smirnov, E. A. Kozhukhova, A. V. Osinsky, and S. J. Pearton, Journal of Vacuum Science \& Technology B 31, 051208 (2013).

${ }^{4}$ U. Honda, Y. Yamada, Y. Tokuda, and K. Shiojima, Japanese Journal of Applied Physics 51, 04DF04 (2012).

5 M. Matsubara and E. Bellotti, "A first-principles study of carbon-related energy levels in gan: Part I - complexes formed by substitutional/interstitila carbon and gallium/nitrogen vacancies," submitted to J. Appl. Phys. (2017).

6 N. Koide, H. Kato, M. Sassa, S. Yamasaki, K. Manabe, M. Hashimoto, H. Amano, K. Hiramatsu, and I. Akasaki, Journal of Crystal Growth 115, 639 (1991).

7 S. Nakamura, T. Mukai, and M. Senoh, Japanese Journal of Applied Physics 31, 2883 (1992).

8 L. B. Rowland, K. Doverspike, and D. K. Gaskill, Applied Physics Letters 66, 1495 (1995).

9 W. Götz, N. M. Johnson, C. Chen, H. Liu, C. Kuo, and W. Imler, Applied Physics Letters 68, 3144 (1996).

10 C. Wetzel, T. Suski, J. W. Ager III, E. R. Weber, E. E. Haller, S. Fischer, B. K. Meyer, R. J. Molnar, and P. Perlin, Phys. Rev. Lett. 78, 3923 (1997).

11 J. Neugebauer and C. G. Van de Walle, Applied Physics Letters 69, 503 (1996).

12 T. Mattila and R. M. Nieminen, Phys. Rev. B 55, 9571 (1997).

13 D. O. Demchenko, I. C. Diallo, and M. A. Reshchikov, Phys. Rev. Lett. 110, 087404 (2013).

14 S. G. Christenson, W. Xie, Y. Y. Sun, and S. B. Zhang, Journal of Applied Physics 118, 135708 (2015).

15 S. Nakamura, N. Iwasa, M. Senoh, and T. Mukai, Japanese Journal of Applied Physics 31, 1258 (1992).

16 M. S. Brandt, N. M. Johnson, R. J. Molnar, R. Singh, and T. D. Moustakas, Applied Physics Letters 64, 2264 (1994).

17 M. S. Brandt, J. W. Ager, W. Götz, N. M. Johnson, J. S. Harris, R. J. Molnar, and T. D. Moustakas, Phys. Rev. B 49, 14758 (1994).

18 C. G. Van de Walle, Phys. Rev. B 56, R10020 (1997).

19 J. L. Lyons, A. Alkauskas, A. Janotti, and C. G. Van de Walle, physica status solidi (b) 252, 900 (2015).
20 D. O. Demchenko, I. C. Diallo, and M. A. Reshchikov, Journal of Applied Physics 119, 035702 (2016).

21 P. Bogusławski, E. L. Briggs, and J. Bernholc, Applied Physics Letters 69, 233 (1996).

22 A. F. Wright, Journal of Applied Physics 92, 2575 (2002).

23 J. L. Lyons, A. Janotti, and C. G. Van de Walle, Applied Physics Letters 97, 152108 (2010).

24 J. L. Lyons, A. Janotti, and C. G. Van de Walle, Phys. Rev. B 89, 035204 (2014).

${ }^{25}$ R. P. Tompkins, T. A. Walsh, M. A. Derenge, K. W. Kirchner, S. Zhou, C. B. Nguyen, K. A. Jones, P. Suvarna, M. Tungare, N. Tripathi, and F. S. Shahedipour-Sandvik, Journal of Materials Research 26, 2895 (2011).

26 J. Heyd, G. E. Scuseria, and M. Ernzerhof, The Journal of Chemical Physics 118, 8207 (2003).

27 J. Heyd, G. E. Scuseria, and M. Ernzerhof, The Journal of Chemical Physics 124, 219906 (2006).

28 G. Kresse and J. Furthmüller, Phys. Rev. B 54, 11169 (1996).

29 G. Kresse and D. Joubert, Phys. Rev. B 59, 1758 (1999).

30 C. Freysoldt, J. Neugebauer, and C. G. Van de Walle, Phys. Rev. Lett. 102, 016402 (2009).

31 C. Freysoldt, J. Neugebauer, and C. G. Van de Walle, physica status solidi (b) 248, 1067 (2011).

32 C. Freysoldt, "sxdefectalign," https://sxrepo.mpie.de/ projects/sphinx-add-ons/files.

33 P. O'Hare, I. Tomaszkiewicz, C. Beck, II, and H.-J. Seifert, The Journal of Chemical Thermodynamics 31, 303 (1999).

34 D. Lide, ed., CRC Handbook of Chemistry and Physics (CRC Press, Boca Raton, FL, 2005).

35 S. M. Myers, A. F. Wright, G. A. Petersen, C. H. Seager, W. R. Wampler, M. H. Crawford, and J. Han, Journal of Applied Physics 88, 4676 (2000).

36 A. F. Wright, C. H. Seager, S. M. Myers, D. D. Koleske, and A. A. Allerman, Journal of Applied Physics 94, 2311 (2003).

37 J. L. Lyons, A. Janotti, and C. G. Van de Walle, Phys. Rev. Lett. 108, 156403 (2012).

38 P. Bogusławski and J. Bernholc, Phys. Rev. B 56, 9496 (1997).

39 A. F. Wright, Journal of Applied Physics 98, 103531 (2005).

40 Finite difference method implemented in the VASP code is used. Both positive and negative displacements by $0.015 \AA$ are introduced in the calculations. 
41 M.Drechsler, D.M.Hofmann, B.K.Meyer, T.Detchprohm, H.Amano, and I.Akasaki, Japanese Journal of Applied Physics 34, L1178 (1995).
42 J. I. Pankove, S. Bloom, and G. Harbeke, RCA Review 36, 163 (1975). 